\title{
SEGURANÇA ALIMENTAR E SAÚDE BUCAL: ESTUDOS INTERDISCIPLINARES SOBRE LIMITAÇÕES PARA GARANTIA DA SAÚDE EM UMA COMUNIDADE QUILOMBOLA DO NORTE DO TOCANTINS
}

\author{
Katiane Pereira Braga (D)
}

Instituto Federal de Educação Ciência e Tecnologia do Tocantins | Araguaína - TO - Brasil

Jéssica Guimarães Dias $ه$

Faculdade de Ciência do Tocantins | Araguaína - TO - Brasil

Sabrina Guimarães Paiva $ه$

Instituto Federal de Educação Ciência e Tecnologia do Tocantins | Araguaína - TO - Brasil

Adolfo da Silva Mello $ه$

Faculdade de Ciência do Tocantins I Araguaína - TO - Brasil

Silviene Fabiana Oliveira (D)

Universidade de Brasília | Brasília - DF - Brasil

Priciane Cristina Correa Ribeiro $ه$ 


\section{RESUMO}

Cocalinho é uma comunidade quilombola localizada no norte do estado do Tocantins e, da mesma forma que outras comunidades de ancestralidade africana no Brasil, carece de assistência social adequada e de acesso aos serviços de saúde. Para entender o contexto atual dessa comunidade, vários parâmetros foram analisados: segurança alimentar, frequência de consumo alimentar, dados socioeconômicos e antropométricos, saúde bucal e prevalência de dentes cariados, ausentes e obturados. Os parâmetros avaliados indicaram, como esperado, uma grave falta de acesso à saúde em Cocalinho, o que reforça a necessidade de políticas públicas eficazes para atender às necessidades básicas dessa comunidade. Soluções voltadas ao incentivo da produção agroalimentar e à educação alimentar e nutricional que valorizem os alimentos regionais, além daquelas voltadas à garantia do acesso aos serviços de saúde, constituem estratégias potenciais para reduzir a pobreza e a má nutrição. Coletivamente, os dados destacam a importância de estudos interdisciplinares para melhor caracterizar as comunidades tradicionais, a fim de fornecer dados relevantes para políticas públicas adequadas.

Palavras-chave: segurança alimentar; saúde; nutrição; vulnerabilidade; desenvolvimento.

\section{FOOD SECURITY AND ORAL HEALTH: INTERDISCIPLINARY STUDIES ON THE LIMITATIONS FOR HEALTH GUARANTEE IN A QUILOMBOLA COMMUNITY FROM THE NORTH OF TOCANTINS}

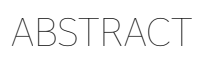

Cocalinho is a quilombola community located in the north of the state of Tocantins and similarly to other African descendant communities in Brazil, it lacks proper social assistance and healthcare access. In order to understand the current context of this community, several parameters were analyzed: food security, frequency of food consumption, socioeconomic status, anthropometric data, oral health, and the prevalence of decayed, missing and filled teeth. As expected, the evaluated parameters indicated a severe lack of healthcare access in Cocalinho, which reinforces the need for effective public policies to meet the basic needs of this community. Solutions aimed at encouraging agrifood production, food and nutrition education that value regional foods, in addition to improvements in access to health services, are potential strategies to reduce poverty and malnutrition. Collectively, the data highlight the importance of interdisciplinary studies to better characterize traditional communities, in order to provide relevant data for appropriate public policies.

Keywords: food security; health; nutrition;

\section{SEGURIDAD ALIMENTARIA Y SALUD ORAL: ESTUDIOS INTERDISCIPLINARIOS SOBRE LIMITACIONES PARA GARANTIZAR LA SALUD EN UNA COMUNIDAD DE QUILOMBOLAS EN EL NORTE DE TOCANTINS}

\section{RESUMEN}

Cocalinho es una comunidad quilombola ubicada en el norte del estado de Tocantins y, al igual que otras comunidades de ancestralidad Africana en Brasil, carece de asistencia social adecuada y acceso a servicios de salud. Para comprender el contexto actual de esta comunidad, se analizaron varios parámetros: seguridad alimentaria, frecuencia del consumo de alimentos, estado socioeconómico, datos antropométricos, salud bucal y prevalencia de dientes cariados, faltantes y obturados. Como se esperaba, los parámetros evaluados indicaron una grave falta de acceso a la salud en Cocalinho, lo que refuerza la necesidad de políticas públicas efectivas para satisfacer las necesidades básicas de esta comunidad. Las soluciones destinadas a fomentar la producción agroalimentaria y la educación alimentaria y nutricional que valore los alimentos regionales, además de aquellas destinadas a garantizar el acceso a los servicios de salud, son estrategias potenciales para reducir la pobreza y la desnutrición. En conjunto, estos datos destacan la importancia de los estudios interdisciplinarios para caracterizar mejor a las comunidades tradicionales, con el fin de proporcionar datos relevantes para políticas públicas apropiadas.

Palabras clave: seguridad alimentaria; salud; nutrición; vulnerabilidad; desarrollo. 


\section{INTRODUÇÃ $0^{1}$}

A definição de quilombo comumente se refere a comunidades formadas por africanos e/ou afrodescendentes escravizados, fugidos e refugiados em locais de difícil acesso, sendo que seus moradores são denominados quilombolas. Contudo, a definição das comunidades denominadas como "remanescentes de quilombos", na contemporaneidade, pode ser encontrada no Decreto $\mathrm{n}^{\circ} 4.887$, artigo $2^{\circ}$, de 20 de novembro de 2003, da Presidência da República, vejamos: "[...] grupos étnico-raciais, segundo critérios de autoatribuição, com trajetória histórica própria, dotados de relações territoriais específicas, com presunção de ancestralidade negra relacionada com a resistência à opressão histórica sofrida" (Brasil 2003).

Ressalta-se, ainda, que comunidades quilombolas se enquadram na definição legal de populações tradicionais. $\mathrm{O}$ decreto presidencial $\mathrm{n}^{\circ} 6.040$, de 7 de fevereiro de 2007, conceitua populações tradicionais como:

\footnotetext{
Grupos culturalmente diferenciados e que se reconhecem como tais, que possuem formas próprias de organização social, que ocupam e usam territórios e recursos naturais como condição para sua reprodução cultural, social, religiosa, ancestral e econômica, utilizando conhecimentos, inovações e práticas gerados e transmitidos pela tradição.
}

De acordo com a Fundação Cultural Palmares (s/d),

[...] [a] comunidade remanescente
de quilombo é um conceito político-
jurídico que tenta dar conta de uma
realidade extremamente complexa e
diversa, que implica a valorização de
nossa memória e o reconhecimento da
dívida histórica e presente que o Estado
brasileiro tem com a população negra.

Seguindo essa linha, Paiva et al. (2020) argumentaram que o conceito necessita ser ainda discutido por órgãos governamentais e de política pública, para que comunidades afro-derivadas, com histórias de formação distintas do entendimento comum, sejam também reconhecidas como remanescentes de quilombos.

Comunidades quilombolas possuem histórias particulares, formando um grupo coeso em sua ancestralidade africana, na sua cultura e na luta contra a opressão. Os dados da Fundação Cultural Palmares indicam que, no estado do Tocantins, existem 45 comunidades quilombolas certificadas. Não se sabe ao certo quantos quilombos existem hoje no Brasil, mas cerca de 3.000 comunidades tiveram suas certificações emitidas e várias outras iniciaram o processo de reconhecimento (Fundação Cultural Palmares 2020). A Constituição Federal de 1988, no seu artigo 68, do Ato das Disposições Constitucionais Transitórias (ADCT), reconhece o

1 Pesquisa desenvolvida com o apoio da Coordenação de Aperfeiçoamento de Pessoal de Nível Superior (CAPES). 
direito à terra destas comunidades, como destacado a seguir: "aos remanescentes das comunidades dos quilombos que estejam ocupando terras é reconhecida a propriedade definitiva devendo o Estado emitir títulos respectivos” (Brasil 1988:160).

Embora numerosas em todo o território brasileiro, as comunidades quilombolas não apresentam densidade demográfica significativa, e ocupam uma área correspondente a 0,12\% do território nacional (IBGE 2012). Apesar do reconhecimento legal e do direito à terra, a maneira como os aspectos culturais e históricos influenciaram o modo de vida dos remanescentes quilombolas mostra que, em termos socioeconômicos, estas comunidades configuramse como marginalizadas. Indicativos disso são as altas taxas de desemprego, de morbidade, de mortalidade e as baixas taxas de escolaridade observadas nessas populações (Freitas et al. 2011; Brasil 2014b; Durand \& Heidemann 2019).

As condições de vulnerabilidade social se refletem no estado de saúde e nutrição deste grupo, em especial no que tange à segurança alimentar e nutricional (SAN) e à saúde bucal. Apesar do acesso à alimentação ser reconhecido como um direito humano essencial, a fome atrelada à pobreza constitui-se em um dos grandes desafios mundiais e é preocupação central da Organização das Nações Unidas (ONU). Neste contexto, foi criada, em 1974, durante a primeira
Conferência Mundial de Alimentos, a Organização das Nações Unidas para Alimentação e Agricultura (Food and Agriculture Organization of the United Nations - FAO), organização multigovernamental para o incentivo da agricultura e da alimentação saudável. Segundo dados da FAO, o Brasil, ao deixar o mapa da fome em 2014, tornou-se uma referência na articulação de políticas para o combate à fome (FAO 2014).

A segurança alimentar representa um estado no qual todas as pessoas, em todos os momentos, têm acesso econômico a alimentos suficientes, seguros e nutritivos para satisfazer às suas necessidades dietéticas (FAO 1996). Já a insegurança alimentar (IA) está relacionada à pobreza e tradicionalmente está ligada à desnutrição. Entretanto, o paradoxo nutricional proposto há mais de 15 anos nos Estados Unidos evidencia também a associação entre IA e excesso de peso (Dietz 1995; Kursmark \& Weitzman 2009). Embora determinados estudos apontem um estado de insegurança alimentar envolvendo populações quilombolas (Cordeiro et al. 2014; Sousa et al. 2019; E. Silva et al. 2017), ainda há lacunas do conhecimento a serem compreendidas. Cerca da metade $(47,8 \%)$ dos quilombolas vive em casas com insegurança alimentar grave, com as regiões Norte e Nordeste enfrentando a situação mais crítica (Gubert et al. 2016). Estudos envolvendo comunidades do 
Tocantins evidenciaram a prevalência elevada de obesidade (Paiva 2017) e síndrome metabólica entre mulheres quilombolas (Luisi et al. 2019), o que, possivelmente, se relaciona a mudanças de hábitos e padrões nutricionais dessas comunidades.

Em relação aos quilombolas, a Pesquisa de Avaliação da Situação de Segurança Alimentar e Nutricional em Comunidades Quilombolas Tituladas, promovida pelo então Ministério do Desenvolvimento Social e Combate à Fome (incorporado ao Ministério da Cidadania em 2019), em parceria com várias instituições colaboradoras, por meio de uma amostragem incluindo 169 comunidades das cinco regiões do país, apontou a prevalência de SAN em 55,6\% das famílias investigadas, não sendo incluídas as comunidades quilombolas do estado do Tocantins (Brasil 2014b).

As políticas públicas de SAN visam estimular as tradicionalidades dos quilombolas, de grupos indígenas, grupos de mulheres rurais, assentados de reforma agrária, pescadores artesanais e agricultores familiares, em todas as regiões do país, no entanto estes atores dependem do reconhecimento do seu território e de sua identidade, tornando esse processo mais moroso e ineficiente (Sardinha et al. 2014). Neste cenário, surge a necessidade de evidenciar os problemas quanto à segurança alimentar e nutricional, bem como à saúde bucal nas comunidades quilombolas do Tocantins.

As doenças bucais acometem mais as comunidades socialmente vulneráveis (Matheus 2010). Ademais, indicadores sociais característicos das comunidades quilombolas, como o baixo poder socioeconômico, o baixo nível educacional e a falta de emprego, mostram-se associados ao menor acesso aos serviços odontológicos e aos conhecimentos básicos sobre saúde e higiene bucal (Duarte 2014). No Brasil, a saúde bucal foi incluída no Sistema Único de Saúde (SUS) no final da década de 80 , quando o sistema ganhou novas diretrizes para a sua descentralização e para a reforma sanitária (Brasil 2005). Porém, a garantia da equidade desse sistema continua se configurando como um grande desafio no país. No período de 2004 a 2015, com o marco do Programa Brasil Sorridente (BS), que guiou a maior Política Nacional de Saúde bucal executada no país, os investimentos nas ações públicas neste âmbito foram significativos, nas ações de promoção, prevenção e recuperação da saúde bucal (Brasil 2005). Estes investimentos financiaram também as ações da Agenda Social Quilombola (ASQ).

A ASQ é considerada um marco das lutas dos movimentos sociais quilombolas e foi instituída pelo decreto $\mathrm{n}^{\circ} 6.261 / 2007$, como parte do Programa Brasil Quilombola, lançado pelo governo federal (Arantes et al. 2014). Na agenda, estão incluídos 
todos os direitos que devem ser concedidos a essas comunidades, como aqueles relacionados à educação, à saúde geral e bucal, à cultura, à segurança alimentar, à agricultura, entre outros (Morais 2012; Dias et al. 2020).

Embora ocorram incentivos de projetos de atendimento às populações quilombolas, a fim de reduzir as desigualdades étnico-raciais e a discriminação nas instituições e serviços do SUS (Brasil 2009), o acesso e a acessibilidade aos serviços de saúde ainda se revelam precários para as comunidades quilombolas no Norte do Brasil. Por meio da Fundação Nacional de Saúde (FUNASA) e da Política Nacional de Saúde Integral da População Negra, tais projetos são instituídos, porém ainda são ineficientes no atendimento das especificidades geográficas e socioculturais nesta região (Cavalcante 2011; Cavalcante \& Silva 2019).

$\mathrm{Na}$ tentativa de compreender as limitações para a promoção da saúde em uma comunidade tradicional, o trabalho aqui apresentado buscou relacionar dados de dois estudos transversais interdisciplinares sobre a segurança alimentar e a saúde bucal em Cocalinho, um quilombo contemporâneo do norte do Tocantins. A proposta buscou, ainda, avaliar o papel das políticas públicas diretamente relacionadas aos aspectos nutricionais e bucais no estado de saúde dessa comunidade.

\section{MÉTODOS}

\subsection{LOCAL DE ESTUDO E ESTRATO POPULACIONAL AMOSTRADO}

O presente trabalho sintetiza resultados de duas pesquisas de delineamento transversal, com estratificação aleatória simples realizada na comunidade quilombola de Cocalinho, localizada em um povoado do município de Santa Fé do Araguaia (Figura 1). O município possui 7.512 habitantes e se localiza a $496,6 \mathrm{~km}$ da capital Palmas, fazendo parte da microrregião do município de Araguaína (IBGE 2018).

Como a maioria das comunidades quilombolas do extremo norte do Tocantins, a formação de Cocalinho ocorreu quando famílias oriundas, em sua maioria, do Maranhão se estabeleceram na região. Tem-se conhecimento de que as frentes de expansão da Romaria Negra iniciaram na década de 50, na microrregião do Araguaia, sendo uma com origem em Goiás e a outra no Maranhão (Velho 2009). A comunidade de Cocalinho foi reconhecida pela Fundação Cultural Palmares, em 2006, e na atualidade apresenta 272 quilombolas registrados no povoado, segundo dados da Associação Quilombola da referida comunidade. Trata-se de um grupo social com historicidade marcada pela resistência e pela luta por seus direitos como quilombolas, com cultura e personalidade próprias, observadas no contexto social e pessoal, porém com acesso 
limitado a serviços de saúde.

Considerando os dois estudos aqui apresentados, um abordou a análise da segurança alimentar e nutricional de adultos, tendo como parâmetros indicadores de saúde os índices de Segurança Alimentar e Nutricional (SAN), os indicadores antropométricos (peso, circunferência abdominal e índice de massa corporal) e a frequência de acesso das famílias quilombolas aos grupos alimentares (FA); e o outro abordou a saúde bucal de escolares da comunidade, levantando como indicadores, além do índice SAN e FA das famílias, o índice de CPOD (índice de avaliação: dentes Cariados, Perdidos e Obturados) do escolar investigado.

Portanto, a composição geral da amostra, considerando-se ambos os estudos, investigou dois estratos populacionais: (1) famílias quilombolas (residentes na comunidade), que foram recrutadas

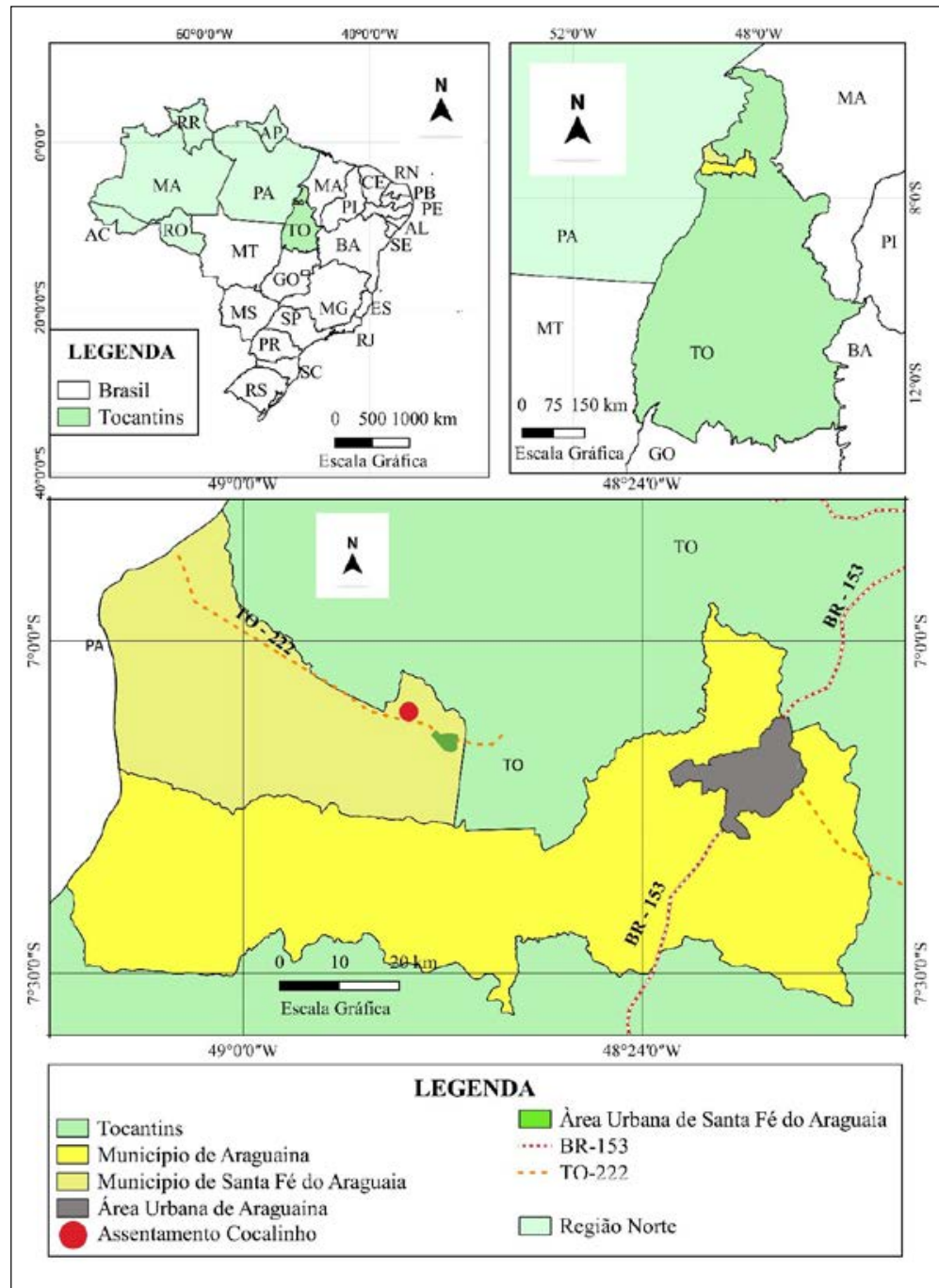

Figura 1 - Mapa do estado do Tocantins, destacando o município de Santa Fé do Araguaia com a localização da comunidade quilombola de Cocalinho, e a cidade vizinha, Araguaína, por onde passa a BR-153 (referência da Belém-Brasília). Fontes: IBGE (2010) e Tocantins-SEPLAN (2012). Mapa: A. França (2020). por meio de visitas domiciliares ou durante atendimentos na Unidade Básica de Saúde da comunidade ou em ação de extensão em saúde e alimentação, promovida na Escola Municipal Emanuel; e (2) estudantes recrutados durante uma segunda ação de extensão de saúde bucal, planejada em parceria com a direção da escola, para garantir a presença dos pais ou responsáveis pelos alunos durante o recrutamento. Ressalta-se que, na referida comunidade, há uma única Unidade Básica de Saúde e uma única escola.

Os estudos foram submetidos e aprovados pelo Comitê de Ética em Pesquisa, sob pareceres: CEP/ IFTO campus Palmas, parecer $n^{\circ} 2.621 .825$, e CEP/ 
UFT, campus Palmas, CAAE 03629018.0.1001.5519. Nos locais e momentos definidos para a coleta dos dados, os pesquisadores se apresentaram e explicaram os objetivos dos estudos para os líderes comunitários e os membros das famílias. Na sequência, as eventuais questões técnicas foram respondidas e a participação voluntária foi solicitada.

\subsection{COLETA E ANÁLISE DOS DADOS}

Antes da realização do estudo, foi feito um processo de equiparação de qualidade dos procedimentos dos responsáveis pela aplicação dos questionários e pelas medidas antropométricas, com inferência de 20 pessoas para padronizar o método de coleta dos dados.

Os dados sociais e econômicos foram coletados por meio de um questionário, com base nos conceitos de determinantes sociais e insegurança alimentar (Kepple \& Segall-Corrêa 2011 e discussões da Associação Brasileira de Empresas de Pesquisa - $\mathrm{ABEP}^{2}$ ). O grau de segurança alimentar e estado nutricional da comunidade foi avaliado por meio da Escala Brasileira de Insegurança Alimentar (EBIA) e um Questionário de Frequência Alimentar (QFA).

A EBIA foi elaborada pelo Departamento de Agricultura dos Estados Unidos (USDA) e foi adaptada e validada pela Universidade Estadual de Campinas (UNICAMP), sendo amplamente utilizada nos estudos de Pesquisa Nacional de Domicílios (PNAD), pelo Instituto Brasileiro de Geografia e Estatística (IBGE), Ministério de Desenvolvimento Social (MDS), Ministério da Saúde (MS) e FAO (Brasil 2014a). A versão utilizada da EBIA nos dois estudos foi composta por seis perguntas, que se referem aos últimos doze meses do participante em relação à alimentação (Apêndice 1). As informações permitem a classificação nas categorias segurança alimentar (SA), insegurança alimentar moderada (sem fome) (IA) e insegurança alimentar grave (com fome) (IA grave).

O Questionário de Frequência Alimentar (QFA) foi elaborado com base na alimentação habitual da região, desta forma, todas as frequências citadas foram transformadas em frequência diária, para que fosse medida como uma unidade de tempo (Pedraza \& Nobre 2014). Para a avaliação da frequência alimentar, os alimentos foram agrupados em proteínas, carboidratos, açúcares (sendo este do grupo de carboidratos), hortaliças e frutas (Apêndice 2), conforme o "Guia alimentar para a população brasileira” (Brasil 2006), e ainda classificados em processados industrializados (ID) e não industrializados (NID). Em seguida, foram classificados em consumo adequado e

2 Esta classificação é adotada desde 2015, e é descrita no livro "Estratificação socioeconômica e consumo no Brasil" (Kamakura \& Mazzon 2013). 
inadequado, sendo que, para esta última análise, foram utilizadas as recomendações do Ministério da Saúde (Brasil 2006, 2014a).

Foram obtidas medidas antropométricas (peso, altura e circunferência abdominal) e o cálculo de Índice de Massa Corporal (IMC) de adultos no momento da visita domiciliar do estudo. Para a coleta das medidas antropométricas, foram utilizadas balanças e estadiômetros portáteis digitais, modelo TEC-SILVER PM, previamente calibrados, e fita métrica inelástica (Vonder), com capacidade de $150 \mathrm{~cm}$ e precisão de $0,1 \mathrm{~cm}$. A altura foi aferida na posição ortostática, braços estendidos ao longo do corpo, cabeça erguida, sendo utilizado o estadiômetro acoplado da balança antropométrica. A circunferência abdominal (CA) foi mensurada no ponto médio, situado entre a crista ilíaca e o último arco costal, com fita métrica inelástica (Fontoura \& Formentin 2013).

Durante o recrutamento do estrato populacional das famílias, foi selecionado apenas um adulto por domicílio com idade mínima de 18 anos para responder ao questionário de EBIA. Já para a coleta de medidas antropométricas, foram incluídos todos os membros da família maiores de 18 anos, encontrados no domicílio.

O recrutamento do estrato populacional dos adolescentes, que formaram a amostra para coleta de dados de saúde bucal, foi realizado na escola após os responsáveis autorizarem a participação e responderem ao questionário de segurança alimentar (EBIA) e hábitos alimentares (QFA), constituindo um conjunto de dados analisados em paralelo.

Na avaliação da saúde bucal, foi utilizado o índice CPOD, sendo o dente a própria unidade de medida. O índice foi descrito em 1937, por Klein e Palmer, e é usado mundialmente, sendo a idade de 12 anos preconizada para a avaliação básica, principalmente para planejamento e avaliação de programas de assistência e prevenção odontológica. O CPOD envolve muitos fatores quando utilizado em levantamentos epidemiológicos de larga escala, como necessidade de tratamento e de avaliação tanto da coroa do dente quanto da raiz, porém, nesta pesquisa, evidenciaremos dados apenas da avaliação da coroa dentária (Schmidt 2001).

Para avaliação da saúde bucal, foram incluídos adolescentes quilombolas, entre 12 e 17 anos, com a dentição permanente completa. A coleta desses dados ocorreu após a calibração de todos os examinadores, que, no caso, foram três equipes, formadas por um examinador (dentista) e um anotador. O processo de calibração seguiu todos os requisitos da Organização Mundial da Saúde (WHO 1993), descritos no estudo SB (Brasil 2010, 2012). A partir dos dados coletados, foi feito um cálculo: "número total de 
dentes permanentes cariados, perdidos e obturados de cada examinado", dividido pelo "número total de crianças examinadas”. O resultado do cálculo seguiu a seguinte interpretação: 0,0 a 1,1 muito baixo; 1,2 a 2,6 - baixo; 2,7 a 4,4 - moderado; 4,5 a 6,5 - alto; 6,6 e mais - muito alto. O valor elevado deste índice está associado a piores condições de saúde bucal da população (Brasil 2012).

$\mathrm{Na}$ Tabela 1, são apresentadas as características gerais dos participantes incluídos nos dois estudos, bem como as variáveis investigadas em cada um deles. As análises estatísticas foram realizadas por meio do programa Statistical Package for the Social Sciences (SPSS) v.2.1 IBM, utilizando os testes ANOVA, qui-quadrado, correlação, regressão logística simples e multinomial. Para a análise estatística, foram agrupados os dados de antropometria em categorias de índices adequados e inadequados, conforme as diretrizes da Sociedade Brasileira de Cardiologia (SBC), para compreensão de risco para desenvolvimento de doenças crônicas e cardiovasculares (SBC 2013).

\section{RESULTADOS E DISCUSSÃO}

\subsection{LIMITAÇÕES PARA A GARANTIA DA} SAÚDE NA COMUNIDADE REMANESCENTE

\section{QUILOMBOLA DE COCALINHO}

A média de idade dos adultos participantes foi de 44,9 anos, enquanto a dos adolescentes participantes foi de 14,5 anos. A autodeclaração étnico-racial foi requerida apenas para a amostra dos adultos, onde a maioria se autodeclarou negro (68\%), como esperado por se tratar de uma comunidade afrodescendente. Os demais (32\%) se declararam pardos e outros. Embora os dados de segurança alimentar e nutricional tenham sido coletados para os dois grupos, os referentes à amostra de adolescentes serão apresentados no tópico seguinte, onde foram melhor relacionados com os dados de saúde bucal desta amostra. Portanto, a partir daqui, os dados apresentados referem-se apenas ao estrato amostral dos adultos. 
Os dados da EBIA permitiram observar que 45\% dos adultos apresentam segurança alimentar, $17 \%$ insegurança alimentar sem fome (moderada) e $38 \%$ com insegurança alimentar grave.

A média salarial da amostra foi de 803,83 reais; onde 75,80\% dos indivíduos da população recebem até um salário mínimo e, destes, 65,95\% têm algum grau de insegurança alimentar. Já entre os indivíduos que relataram não ter renda, 75\% apresentaram um status de insegurança alimentar grave, que é a insegurança associada à fome. Entre aqueles participantes que relataram receber acima de um salário mínimo $(17,74 \%)$, a maioria $(90,9 \%)$ foi classificada no status de segurança alimentar. Este resultado atesta que, quanto maior a renda, maior é o acesso a alimentos variados e de boa qualidade.

É importante salientar que, no Brasil, a renda per capita para a zona urbana é quase três vezes maior que para a zona rural (FJP 2017), assim os dados observados em Cocalinho seguem o cenário nacional. Contudo, chama a atenção o fato de que, mesmo estando em condições evidentes de pobreza, a frequência de pessoas com benefícios de transferência de renda, como o Programa Bolsa Família (PBF), é baixa, e que, conforme informação da equipe da Estratégia de Saúde da Família (ESF), que assiste à comunidade, a cada ano, reduz-se o número de beneficiados, que, em três anos, passou de 44 para 25 famílias beneficiadas na comunidade, ou seja, apenas 13 $(20,96 \%)$ do total de famílias investigadas acessam o benefício.

Buscando-se uma avaliação entre os fatores socioeconômicos e o grau de segurança alimentar na população adulta, foi realizada uma análise de associação que evidenciou a renda e a quantidade de pessoas que vivem na casa como fatores associados às categorias da EBIA (Tabela 2). Para o parâmetro "número de pessoas que moram na casa”, observou-se que, quando há mais de quatro pessoas no mesmo domicílio $(68,56 \%)$, ocorre insegurança alimentar em algum grau $(\mathrm{p}=0,031)$, assim como observado por Salles-Costa et al. (2008). Aliado a tal cenário, Paiva (2017) descreveu que as populações afrodescendentes tendem a estar nas classes econômicas mais baixas da sociedade, como encontrado na totalidade da amostra da população de Cocalinho, estratificada como D $(58,06 \%)$ e E $(41,93 \%)$, o que contribui para o estado nutricional dessa comunidade.

Apesar dos demais parâmetros estudados não terem sido associados ao grau de segurança alimentar na presente comunidade, os resultados obtidos neste estudo são fatores reconhecidamente associados à condição de insegurança alimentar e vulnerabilidade dos quilombolas (L. Santos 2014). 
Tabela 2 - Distribuição sociodemográfica em relação à EBIA de 62 indivíduos da Comunidade Remanescente Quilombola de Cocalinho, em Santa Fé do Araguaia, Tocantins. Legendas: $\mathrm{N}^{\circ}$ ind = número de indivíduos; SA = Segurança Alimentar; IAM = Insegurança Alimentar Moderada; IAG = Insegurança Alimentar Grave; Teste de qui-quadrado $=\chi 2 ; \mathrm{GL}=$ graus de liberdade; $p<0,05$ : associação significativa indicada em negrito. Números entre parênteses indicam os percentuais referentes aos valores absolutos que constam fora dos parênteses.

\begin{tabular}{|c|c|c|c|c|c|c|c|}
\hline VARIÁVEL & $\mathrm{N}^{0}$ ind $(\%)$ & SA (\%) & IAM (\%) & IAG (\%) & $\chi^{2}$ & GL & Valor de p \\
\hline \multicolumn{8}{|l|}{ GÊNERO } \\
\hline Masculino & $13(19,35)$ & $9(66,66)$ & $1(8,33)$ & $3(25)$ & 33,03 & 1 & 0,159 \\
\hline Feminino & $49(80,64)$ & $19(38)$ & $10(20)$ & $20(42)$ & & & \\
\hline \multicolumn{8}{|l|}{ RAÇA/COR } \\
\hline Negro & $42(67,74)$ & $20(48,83)$ & $6(13,95)$ & $16(34,88)$ & 2,879 & 1 & 0,222 \\
\hline Pardos/Outros & $20(32,25)$ & $6(30)$ & $5(25)$ & $9(45)$ & & & \\
\hline \multicolumn{8}{|l|}{ IDADE } \\
\hline$<25$ & $6(9,67)$ & $5(83,33)$ & - & $1(16,66)$ & & & 0,6551 \\
\hline $26-40$ & $23(37,09)$ & $7(30,43)$ & $5(21,73)$ & $11(47,82)$ & & & \\
\hline $41-60$ & $22(35,48)$ & $10(45,45)$ & $3(13,63)$ & $9(40,90)$ & 0,200 & 1 & \\
\hline$>65$ & $11(17,74)$ & $5(44,6)$ & $3(27,27)$ & $3(27,27)$ & & & \\
\hline \multicolumn{8}{|l|}{ ESCOLARIDADE } \\
\hline $\begin{array}{c}\text { Nenhuma/ } \\
\text { Fundamental }\end{array}$ & $27(43,54)$ & $12(44,44)$ & $3(11,11)$ & $12(44,44)$ & & & 0,430 \\
\hline Ensino Médio & $24(38,70)$ & $10(45,83)$ & $6(25)$ & $7(29,16)$ & 0,644 & 1 & \\
\hline Superior & $11(17,74)$ & $4(36,36)$ & $2(18,18)$ & $5(45,45)$ & & & \\
\hline \multicolumn{8}{|l|}{$\begin{array}{c}\text { NÚMERO DE } \\
\text { PESSOAS NA CASA }\end{array}$} \\
\hline $2-3$ & $27(43,54)$ & $16(59,25)$ & $3(11,11)$ & $8(29,62)$ & 2,879 & 1 & $\mathbf{0 , 0 3 1}$ \\
\hline$>4$ & $35(56,45)$ & $11(31,42)$ & $8(22,85)$ & $16(45,71)$ & & & \\
\hline \multicolumn{8}{|l|}{ RENDA } \\
\hline Sem renda & $4(6,45)$ & $1(25)$ & - & $3(75)$ & & & 0,01 \\
\hline Até um salário & $47(75,80)$ & $16(34,04)$ & $11(23,40)$ & $20(42,55)$ & 0,980 & 1 & \\
\hline Acima de um salário & $11(17,74)$ & $10(90,90)$ & - & $1(9,09)$ & & & \\
\hline
\end{tabular}


Os resultados indicaram que a renda e a quantidade de pessoas que vivem na casa são fatores que estão, possivelmente, mais estritamente associados aos índices da EBIA, e foi evidenciado que a insegurança alimentar grave esteve mais acentuada naqueles com menor renda ou que vivem sem renda. Segundo a FAO (2014), as desigualdades de renda afetam a aquisição de alimentos em quantidade e qualidade, tendo impacto direto na segurança alimentar e nutricional. De fato, há uma associação da pobreza e da insegurança alimentar com as desigualdades sociais, conceitos que são, comumente, vistos como sinônimos, provavelmente, pelo fato de que as duas situações se complementam em sua complexidade de mazelas na população afetada. Portanto, pode-se dizer que a pessoa que vive em situação de pobreza está sob privação de suas demandas básicas, como indicado pela falta de alimento, pela moradia inadequada ou por não poder atender outras necessidades para manter sua integridade fisica e mental (Hoffmann 1995; Lavinas 2002).

Dados da FAO (2014) demonstraram a evolução das condições de renda das pessoas beneficiadas com o PBF e, em consequência disso, a redução de problemas nutricionais, o que, todavia, não representa uma garantia de qualidade da nutrição e dos hábitos alimentares. Nesse contexto, avaliou-se a frequência de consumo de nutrientes, de acordo com a preconização do "Guia alimentar para a população brasileira” (Brasil 2006): carboidratos devem compor de $55 \%$ a $75 \%$ da dieta diária. O estudo mostrou baixa ingestão de carboidratos $(43,46 \%)$. Alimentos como a mandioca, que junto com o milho, o feijão e a cana-de-açúcar fazem parte daqueles tradicionalmente associados à cultura africana, não foram corriqueiramente mencionados na alimentação das famílias. A falta do incentivo financeiro para plantar, possivelmente, representa um dos fatores que poderia explicar esta perda de consumo de alimentos tradicionais do costume alimentar quilombola.

Existem políticas públicas voltadas à segurança alimentar e nutricional e as comunidades remanescentes de quilombos deveriam receber este benefício, em decorrência de programas específicos de incentivo ao campo, porém não é o caso da comunidade em estudo. A crítica que se faz neste sentido é a de que as comunidades deveriam ser avaliadas de forma mais profunda, para que se realizasse a distribuição destes investimentos, e também deveriam ser analisados os fatores que as tornam vulneráveis à insegurança alimentar e nutricional.

Neste ponto, é assertivo dizer que as políticas públicas específicas para geração de renda, como previstas nas diretrizes do Plano Nacional de Segurança Alimentar e Nutricional (PLANSAN I e II), devem estimular a autoprodução e a melhoria do acesso à educação para este grupo, o que deveria seguir um padrão de caráter permanente, 
possibilitando mudanças socioeconômicas efetivas para as comunidades. O Brasil, por intermédio de ações específicas de combate à insegurança alimentar, tem tentado mudar o cenário nacional. Entretanto, de acordo com levantamento da associação da comunidade de Cocalinhos, o único benefício do conjunto do PLANSAN que a comunidade recebe é o de distribuição de alimentos em forma de cestas básicas.

Para a aplicação do PLANSAN, é necessário que os municípios sejam monitorados e cumpram metas no monitoramento da SAN, para que sejam beneficiados pelos programas de redução da insegurança alimentar e nutricional. No caso da comunidade de Cocalinhos, este programa fica exclusivamente atribuído à equipe de saúde que atende à comunidade, subordinada ao serviço de atenção básica e serviço social do município de Santa Fé do Araguaia. Esta situação corresponde à realidade da região Norte, onde apenas $11 \%$ dos municípios possuem o Conselho Municipal de Segurança Alimentar e Nutricional, e este geralmente está vinculado à secretaria de assistência social (CAISAN 2014).

Existe, de fato, uma dificuldade dos municípios em alimentarem as informações do Sistema de Informação de Segurança Alimentar e Nutricional (SISAN) e, assim, as avaliações e implantação da política de segurança alimentar e nutricional ficam aquém do previsto, dependendo totalmente da gestão vigente

O PLANSAN trouxe algumas políticas de proteção da soberania alimentar em todo território nacional, que surgiram como tentativa de colaborar com os pequenos agricultores, os quais sofrem por décadas os efeitos das políticas neoliberais na produção de alimentos. Resultados como os da comunidade de Cocalinho são frequentes em diversas comunidades, pois muitas perderam a capacidade produtiva e de sustentabilidade econômica (Sardinha et al. 2014). O conceito de soberania alimentar surgiu em 2007 e abrange os hábitos alimentares que compõem a identidade étnico-cultural de uma população. No caso das comunidades remanescentes de quilombos, estas trazem, além disso, uma forma de representar-se na sociedade (S. Silva e R. Santos, 2018).

Quanto aos hábitos alimentares, é possível observar que, na alimentação dos participantes, predomina a ingestão de carboidratos e proteínas, sendo bastante reduzida a ingestão de frutas e hortaliças (Apêndice 3). O consumo de frutas foi mencionado como dependente das frutas disponíveis nas árvores frutíferas nos quintais e, apesar do baixo consumo, os resultados são semelhantes aos dados nacionais (Brasil 2006). As frutas, hortaliças e legumes deveriam compor de $9 \%$ a $12 \%$ do total diário de alimentação, no entanto, isso não ocorreu na comunidade estudada. 
Os carboidratos simples oriundos de farináceos, como pães, biscoitos, macarrão e o açúcar processado, devem ter, juntos, o consumo mínimo na dieta de $10 \%$, e, aqui, apenas o grupo dos açúcares representaram um elevado consumo (14\%). O segundo grupo, o de proteínas, deve compor de $10 \%$ a $15 \%$ da dieta. O consumo de carne e feijão na dieta da população amostrada de Cocalinho indicou elevada ingestão de alimentos da classe de proteínas, principalmente a carne vermelha, seguida do feijão, de frango e peixes (Brasil 2006).

Muitos entrevistados relataram consumo de carne vermelha com facilidade de acesso na região, pois a comunidade é circundada de fazendas produtoras de gado e, consequentemente, o preço é mais acessível do que na região urbana. Quando questionados sobre a caça ou a pesca, referiram quase não existir tal prática, pois a mata foi substituída por pastos. Oliveira (2018) detalha relatos do início da formação do povoado, em que moradores antigos descreveram abundância de animais para caça e também a prática de coleta de frutos nativos como frequente naquele período. Em relação ao grupo de óleos, observou-se baixa ingestão. No entanto, o questionário de hábitos alimentares não teve amplitude para separar o consumo de gorduras saturadas e insaturadas. $\mathrm{O}$ consumo de gorduras e óleos, de todas as fontes, não deve ultrapassar $30 \%$ da dieta diária. As diretrizes da Sociedade Brasileira de Cardiologia (SBC) definem gorduras trans como aquelas obtidas por meios industriais, geralmente tendo como base um óleo vegetal, e que sofre processos químicos por meio industrial (R. Santos et al. 2013).

Em relação ao grau de processamento (Tabela 3), constatou-se que $34,55 \%$ dos alimentos tinham origem industrializada, e o restante, não industrializada $(65,45 \%)$. Entretanto, não foi observada associação entre a frequência do consumo de alimentos, industrializados ou não industrializados, com os graus de segurança alimentar estimados a partir do índice $\operatorname{EBIA}(\mathrm{p}=0,557$ e $\mathrm{p}=0,387)$, o que sugere que os quilombolas estão ingerindo os dois tipos de alimentos proporcionalmente, apesar da maior quantidade de alimentos naturais.

Os resultados do presente estudo indicaram um possível processo de transição alimentar e denotam as mudanças de hábitos alimentares, influenciados por fatores culturais e econômicos, e que ocorre no país, de forma associada à urbanização, à industrialização de alimentos e à mudança de culturas alimentares. Resultados similares foram observados em outras comunidades quilombolas do país, populações ribeirinhas, rurais não tradicionais e indígenas brasileiras (Mingroni-Netto et al. 2009; Piperata et al. 2011; Alvim et al. 2014; Felisbino-Mendes et al. 2014; Fávaro et al., 2015; Soares et al., 2015; Pena et al. 2016; H. Silva et al. 2016; Almeida et al. 2016), e também observados em 
populações africanas (Okop et al. 2015).

Estudos descrevem que, ao longo do tempo, as alterações no padrão alimentar vêm demonstrando uma transição nutricional juntamente com os hábitos urbanos, o sedentarismo e o estresse, possibilitando, assim, o aparecimento de doenças crônicas, como hipertensão arterial sistêmica, doenças cardíacas e diabetes mellitus (Moratoya et al. 2013; Schramm et al. 2004). Mendes (2006) descreve a perda da capacidade produtiva em comunidades do Pará e uma transição alimentar forçada, com a população adquirindo hábitos alimentares mais artificiais, ou seja, mais industrializados. Destaca-se o desrespeito à cultura alimentar, por exemplo, na merenda escolar das escolas das comunidades, onde são oferecidos alimentos como biscoito de água e sal e suco artificial, em vez de incentivar o consumo de alimentos regionais (Mendes 2006).

Ao avaliar o grau de (in)segurança alimentar em relação ao consumo de alimentos, foi possível observar que, independentemente de haver segurança alimentar

Tabela 3 - Distribuição da frequência de consumo de alimentos industrializados e não industrializados, e avaliação da associação em relação à EBIA, entre os 62 indivíduos da Comunidade Remanescente Quilombola de Cocalinho, em Santa Fé do Araguaia, Tocantins. Legendas: N/IND = alimentos não industrializados; IND = alimentos industrializados; GL = graus de liberdade; $\mathrm{p}<0,05$.

\begin{tabular}{|c|c|c|c|c|}
\hline & $\%$ & $\chi^{2}$ & GL & VALOR DE P \\
\hline N/IND & 65,45 & $6,645 \mathrm{~b}$ & 1 & 0,557 \\
\hline IND & 34,54 & $4,194 \mathrm{~b}$ & 2 & 0,387 \\
\hline
\end{tabular}

ou não, o consumo de proteína foi adequado (Mahan et al. 2018; Brasil 2016). Além disso, foi possível observar uma transição dos hábitos nutricionais na comunidade para hábitos alimentares mais industrializados. Desse modo, levantou-se a hipótese de que o consumo destes pode estar relacionado à perda da capacidade produtiva das comunidades - indicada pela falta de áreas de cultivo no território - e à urbanização, neste caso, em especial, a distância da comunidade em relação ao centro urbano é de apenas 6 quilômetros (Figuras 2 e 3), o que facilita a aquisição de alimentos menos naturais. Tudo isso pode ter contribuído para uma prevalência elevada de doenças crônicas não transmissíveis, conforme estudo epidemiológico prévio feito na comunidade (Paiva 2017).

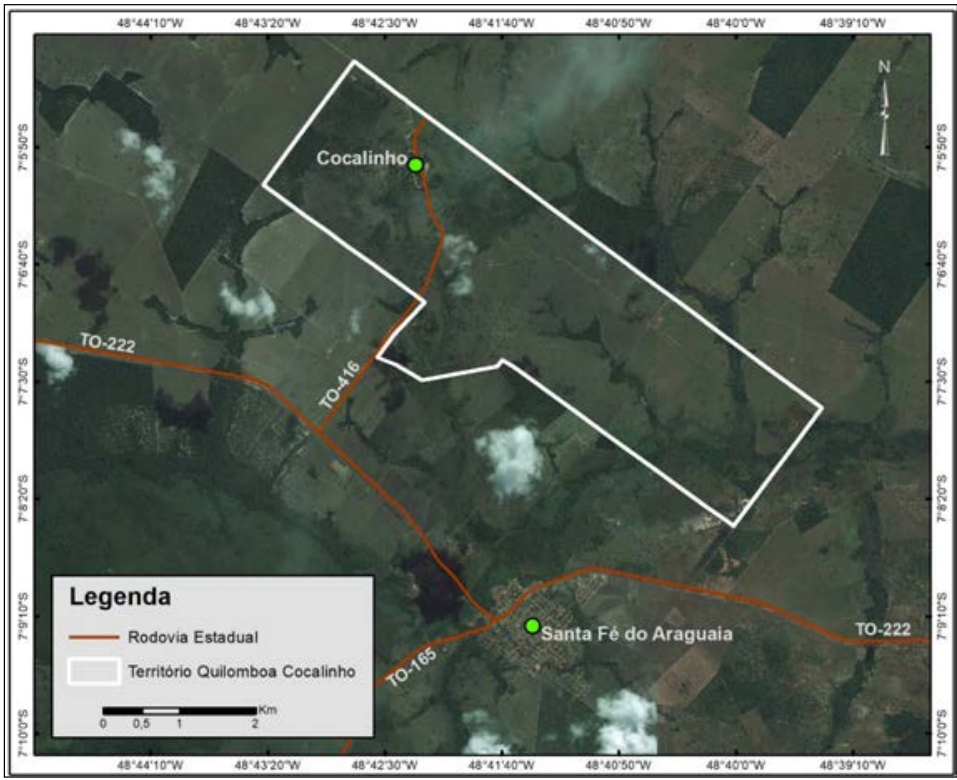

Figura 2 - Imagem de satélite do território quilombola destacando delimitação feita pelo Instituto Nacional de Colonização e Reforma Agrária (INCRA). Fontes: Google Earth (2020) e INCRA (s/d). Elaboração: Benilson Pereira Souza (2020). 


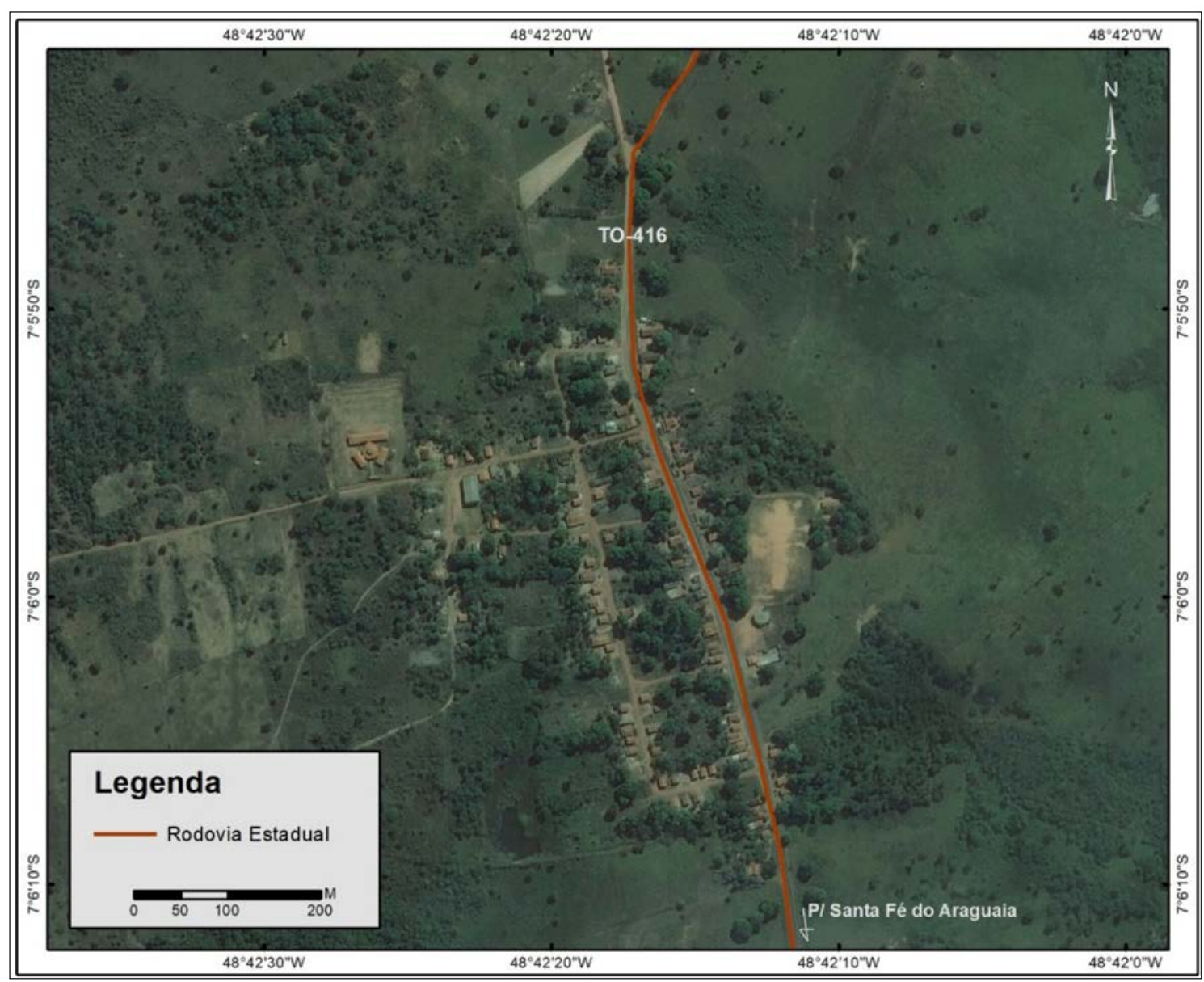

Figura 3 - Imagem de satélite da área onde vive a comunidade de Cocalinho. Fonte: Google Earth (2020).

Os dados da avaliação antropométrica revelaram a ocorrência de sobrepeso e de obesidade entre os quilombolas (Tabela 4), estados relacionados ao grau de insegurança alimentar, corroborando a pré-disposição elevada a doenças cardiovasculares, previamente confirmada em outros estudos (Louzada et al. 2015; Paiva 2017; Mahan et al. 2018; SBC 2013).

Embora a insegurança alimentar (IA) esteja relacionada à pobreza e tradicionalmente encontre- se ligada à desnutrição, um paradoxo nutricional proposto há mais de 15 anos nos Estados Unidos evidencia a associação entre IA e sobrepeso (Dietz 1995; Kursmark \& Weitzman 2009). A IA pode contribuir para o aumento do risco de obesidade, porém isso dependente da idade, além de se apresentar como transitória ou crônica. Schlüssel et al. (2013) revisaram dados brasileiros da Pesquisa Nacional de Demografia e Saúde de 2006 referentes a mulheres adultas (18-49 anos), 
adolescentes do sexo feminino (15 a 19 anos) e crianças com até cinco anos. Um estado de IA grave (IAG) foi associado à maior ocorrência de obesidade entre mulheres adultas e IA moderada (IAM), ao excesso de peso entre adolescentes do sexo feminino, enquanto em crianças de ambos os

Tabela 4 - Avaliação da associação das variáveis: sexo, circunferência abdominal (CA), índice de massa corporal (IMC), atividade física (AF), hipertensão arterial sistêmica/diabetes mellitus (HAS/DM), por regressão logística multinominal. Legendas: $\mathrm{GL}=$ graus de liberdade; $\mathrm{p}<0,05$. Classificação para CA e IMC em AD (adequado) e IN (inadequado). seguros e nutritivos, para satisfazer as suas necessidades dietéticas (FAO 1996). Já a IA está relacionada à pobreza e tradicionalmente está ligada à desnutrição. Em um estudo envolvendo 696 famílias, de 14 comunidade do estado do Tocantins, Monego et al. (2010) verificaram que $589(85,1 \%)$ famílias se encontravam em situação de insegurança alimentar (IA), 258 (37,3\%) apresentaram IA leve, 228 (32,9\%) moderada e 103 (14,9\%) grave. Esses percentuais são apontados como resultado das dificuldades de acesso a bens e serviços, concentração da terra, insuficiência de renda e educação precária (Monego et al. 2010).

sexos nenhuma associação foi observada.

Apesar de mais de 3.000 comunidades já terem

É importante destacar que, apesar do caráter transversal do estudo, pode-se sugerir uma possível transição epidemiológica e nutricional na comunidade, que requer acompanhamento mais pormenorizado e delineamento longitudinal. Quanto à insegurança alimentar, é preciso lembrar que não está relacionada à fome e ao baixo peso apenas, mas também à obesidade. Não é só o acesso à quantidade de alimento que importa, mas também a qualidade nutricional tem influência sobre o estado nutricional de um indivíduo. Assim, a segurança alimentar representa um estado no qual todas as pessoas, em todos os momentos, têm acesso econômico a alimentos suficientes, o título de suas terras, isso não garante o processo produtivo agrícola. Observou-se uma tendência de êxodo rural nesta comunidade em especial, estimulado pela redução de espaço produtivo e pela falta de fomento aos agricultores da comunidade. A luta pelo direito ao território, o desmatamento, a monocultura, a agropecuária e a urbanização têm alimentar desses povos. O respeito aos hábitos alimentares deveria ser uma preocupação também na elaboração de políticas públicas específicas para essas comunidades. A priori, algumas poucas comunidades ainda produzem o seu próprio alimento por meio da horticultura e fruticultura, ameaçado os hábitos tradicionais e a soberania 
além de mandioca, milho, feijão e plantas medicinais. Estas peculiaridades são descritas como resultante da interação com o meio ambiente, dimensão econômica e social de uma população, comumente observada nas comunidades remanescentes de quilombos (Fidelis 2011).

\subsection{SAÚDE BUCAL E NUTRIÇÃO}

Entre os 36 adolescentes quilombolas participantes do presente estudo, 17 (47,22\%) foram categorizados com segurança alimentar, 7 (19,44\%) com insegurança alimentar sem fome (moderada) e $12(33,33 \%)$ com insegurança alimentar grave. Todos foram submetidos à análise de CPOD. A partir dos pontos de corte do índice CPOD, os adolescentes foram categorizados em sua maioria com índices alto e muito alto (Figura 4). Em média, o valor de CPOD verificado foi de 6,1, classificado como alto e bastante superior à média para a idade de 12 anos no Brasil, que é apenas 2,0, valor tido como baixo (M. Silva et al. 2018). Os resultados não indicaram diferença significativa entre os sexos masculino e feminino.

$$
\text { Analisando-se separadamente os }
$$

componentes do CPOD, verificou-se uma elevada média de componentes restaurados, cariados, restaurados com cárie e sem cárie e perdidos, sendo este um cenário bem diferente em relação àqueles encontrados para a capital do estado do Tocantins, Palmas, para a região Norte ou para o Brasil, os quais possuem mais dentes hígidos em seus componentes, menos dentes cariados,

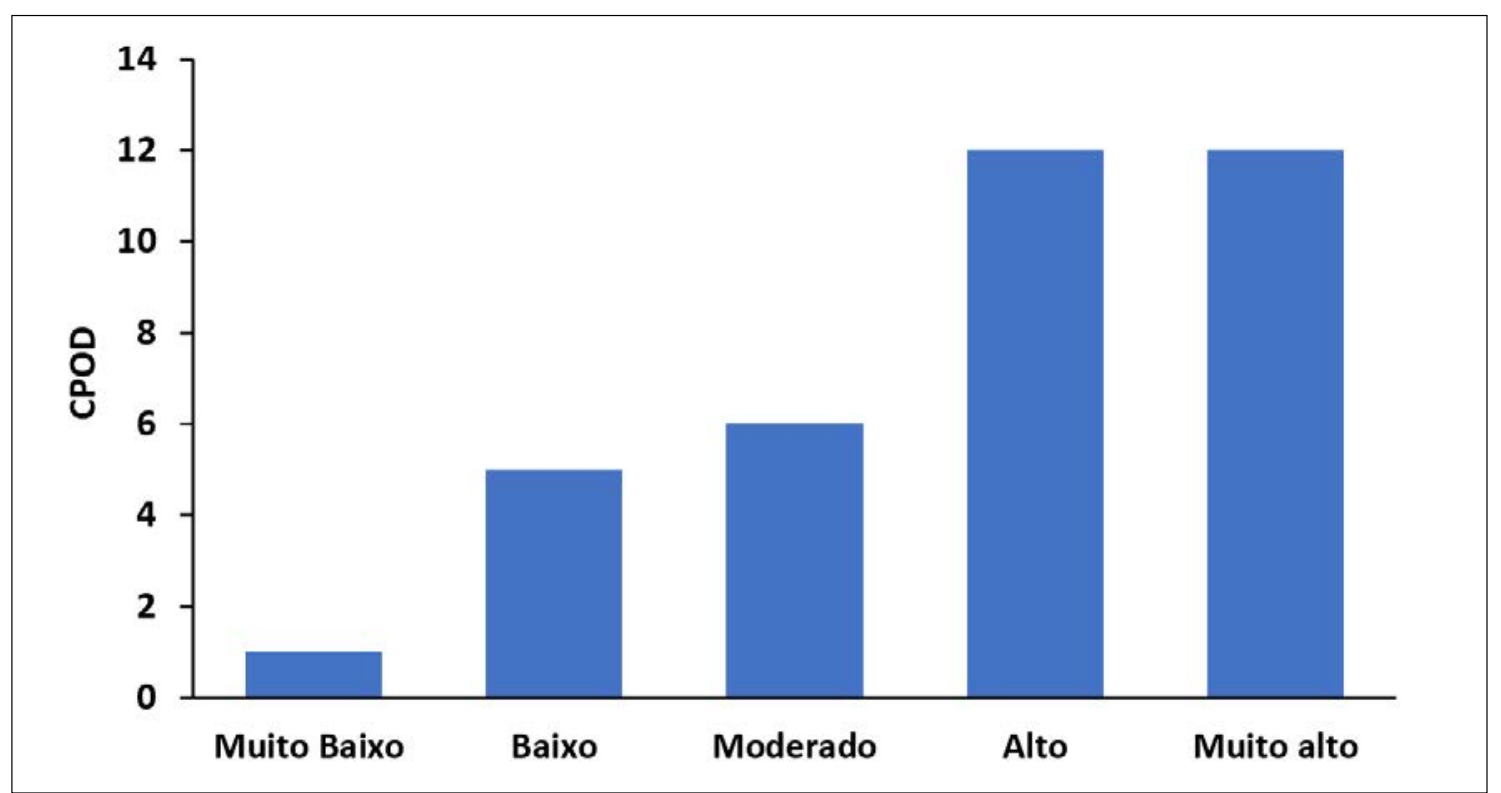

Figura 4 - Gráfico do índice CPOD em 36 adolescentes da comunidade quilombola de Cocalinho, em Santa Fé do Araguaia, Tocantins, a partir dos pontos de corte de acordo com o SB Brasil (Brasil 2010). 
restaurados com e sem cárie e perdidos do que os estudantes da comunidade quilombola. Esta avaliação forneceu um evidente demonstrativo da vulnerabilidade da comunidade de Cocalinho em relação à saúde bucal (Tabela 5). O CPOD de Cocalinho está muito acima da média para a região Norte e para o Brasil, o que possivelmente indica um fenômeno de polarização da cárie dentária, que pode ocasionar perda precoce dos dentes, causando desordens na oclusão dentária, interferindo diretamente no bem-estar e na qualidade de vida das pessoas (Narvai et al. 2006; Dias et al. 2019).

A maioria dos estudos sobre saúde bucal em comunidades quilombolas aponta para falta de acesso a políticas públicas, principalmente preventivas (Dias et al. 2020; Bello \& Souza 2012; Figueiredo et al. 2016; Rodrigues et al. 2011).
Pode-se observar a vulnerabilidade em saúde bucal para essas comunidades, como no estudo realizado no Quilombo de São José da Serra, em Valença, Rio de Janeiro, onde concluiu-se que existe a necessidade de implantação de medidas de atenção à saúde bucal que tenham interferência diretamente na cárie dentária, principalmente na infância, pois o ceo-d (dentes decíduos cariados, extraídos e obturados) foi de 4,3 (Bello \& Souza 2012). Pode-se citar a comunidade quilombola do Sítio Veiga, no município de Quixadá, Ceará, que apresentou jovens na faixa etária de 11 a 15 anos com CPOD de 4,1, considerado moderado (M. Silva et al. 2018).

Esses resultados correspondem a adolescentes com idade entre 12 a 17 anos na comunidade de Cocalinho. Para os resultados equivalentes de Palmas, da região Norte e do

Tabela 5 - Média comparativa dos componentes cariado, perdido e restaurado do índice CPOD dos 36 adolescentes da comunidade quilombola de Cocalinho, em Santa Fé do Araguaia, Tocantins, em relação ao índice do SB Brasil para a capital do estado do Tocantins (Palmas), a região Norte e o Brasil.

\begin{tabular}{llllc}
\hline \multicolumn{1}{c}{ Condição } & Total da Escola Quilombola & $\begin{array}{c}\text { Total } \\
\text { Palmas-To }\end{array}$ & $\begin{array}{c}\text { Total } \\
\text { Região Norte }\end{array}$ & $\begin{array}{c}\text { Total } \\
\text { Brasil }\end{array}$ \\
\hline Hígido & 21,58 & 23,22 & 22,84 & 23,63 \\
\hline Cariado & 2,86 & 1,84 & 2,65 & 1,32 \\
\hline Restaurado com cárie & 0,72 & 0,11 & 0,15 & 0,79 \\
\hline Restaurado & 0,72 & 0,68 & 1,01 & 1,44 \\
\hline Perdido & 0,36 & 0,24 & 1,09 & 1,09 \\
\hline Média final & 6,11 & 2,88 & 4,40 & 3,16 \\
\hline
\end{tabular}


Brasil, temos uma média entre dois grupos de idade para que a comparação seja mais equivalente possível. Esses dados são referentes ao estudo SB Brasil 2010 (Brasil 2012) - último levantamento de saúde bucal realizado pelo Ministério da Saúde, que utiliza grupos de idade para a realização dos exames. Portanto, esses resultados referem-se a uma média do grupo de 12 anos e de 15 a 19 anos.

Os testes de correlação com o índice CPOD não resultaram em associação significativa com a (in)segurança alimentar ou o consumo de alimentos (Tabela 6). No entanto, é preciso ressaltar que os questionários de frequência alimentar e segurança alimentar foram respondidos por responsáveis pelos adolescentes que foram submetidos ao exame do índice CPOD, podendo o consumo de alimentos como guloseimas açucaradas (alimentos cariogênicos) ter sido subestimado pelo entrevistado. Além disso, o baixo número amostral pode ter interferido nos testes estatísticos de associações.

Ressalta-se que a dieta, apesar de ser fundamental para a formação da cárie, não é o fator determinante, pois hábitos de higiene bucal aplicados corretamente, seguidos de métodos preventivos, podem minimizar o processo e impedir a formação da placa bacteriana.

O dente possui o mineral mais duro do corpo humano, porém é suscetível a

Tabela 6 - Resultado dos testes de correlação bivariada (Spearman) realizados com o índice de CPOD e índice de segurança alimentar, frequência diária de consumo de diferentes classes de alimentos, frequência de consumo de alimentos industrializados e não industrializados dos responsáveis da comunidade quilombola de Cocalinho em Santa Fé do Araguaia, Tocantins.

\begin{tabular}{lcc}
\hline \multicolumn{1}{c}{ Variáveis } & P (rho) & Valor de p \\
\hline CPOD e grau de segurança alimentar (SAN) & 0,307 & 0,069 \\
COPD e carboidratos totais & 0,209 & 0,222 \\
CPOD e carboidratos fibrosos & 0,211 & 0,216 \\
CPOD e carboidratos não fibrosos & 0,110 & 0,523 \\
CPOD e proteínas & $-0,150$ & 0,383 \\
CPOD e açúcares & 0,116 & 0,499 \\
CPOD e hortaliças & 0,161 & 0,349 \\
CPOD e alimentos industrializados & 0,169 & 0,325 \\
CPOD e alimentos não industrializados & $-0,003$ & 0,984 \\
\hline
\end{tabular}


lesões, como a cárie, a partir do momento que sofre desmineralização constante. Por outro lado, também ocorre remineralização constantemente, esse fenômeno é conhecido no meio odontológico como "des-re". Historicamente, há indícios de cárie dentária desde o final do período paleolítico, porém, como o consumo de alimentos era, em sua maioria, de origem natural, muitos desses possuíam elementos antimetabólicos, os quais minimizam o efeito "des-re", impedindo a progressão do processo carioso. Além disso, os alimentos naturais proporcionam mecanicamente durante a mastigação o controle de placa bacteriana, que é o principal fator etiológico da cárie dentária (Carvalho 2003; Cavazzola 2003; Moore \& Corbett 1971).

Com o passar dos anos, o homem interferiu na produção dos alimentos, tornando-os mais cariogênicos, por meio do desequilíbrio da cavidade oral. Uma dieta cariogênica é marcada pela presença de carboidratos, principalmente a sacarose. Esse tipo de alimento é metabolizado pelos microrganismos que produzem ácidos orgânicos e desmineralizam a superfície do esmalte dentário (Burt 1988). Contudo, a desmineralização ocorre por um período determinado de tempo, até que a saliva realize a remineralização; por isso, a composição nutricional da dieta não é o único determinante para o processo de cárie, contudo, se a ingestão de alimentos cariogênicos for constante, haverá sim o desequilíbrio do processo "des-re" (Lima 2007).

Uma pesquisa realizada anteriormente, também em Cocalinho e com adolescentes na faixa etária semelhante aos desta pesquisa, mostrou que a comunidade não possui o método com melhor custo/benefício para prevenção de cárie, que é a adição de flúor nas águas de abastecimento. Além disso, o estudo concluiu que a higienização dos examinados variava entre regular e péssima (Dias et al. 2019).

Ademais, um estudo realizado em duas comunidades quilombolas no Rio Grande do Sul, que teve como objetivo compará-las por meio da condição de saúde bucal, sendo uma comunidade abastecida com água fluoretada e a outra não, mostrou que, apesar de as duas comunidades apresentarem problemas socioeconômicos e alta taxa de problemas odontológicos, os desassistidos da adição de flúor na água de abastecimento estavam com as piores condições bucais, com percentual maior de dentes cariados e perdidos, o que ressalta a importância de meios preventivos de cárie, como uso do flúor, principalmente em populações vulneráveis (Figueiredo et al. 2016).

Apesar da adição de flúor na água de 
abastecimento público ser lei no Brasil (Brasil 1974 - Lei n 6.050) e reforçada na Agenda Social Quilombola (Brasil 2007 - Decreto 6.261/2007) como benefício para essas comunidades, muitas sofrem com as consequências de sua ausência. Além disso, há ainda uma questão de regulação de dosagem para algumas comunidades, que sofrem com uma dosagem menor (Rodrigues et al. 2011) e outras com excesso (Conjur 2014), ambos os casos causam prejuízos à saúde bucal da população.

Ademais, existe uma questão de acesso em Santa Fé do Araguaia, Tocantins, pois há apenas dois cirurgiões-dentistas na saúde pública para atender todo o município, sendo um para a zona rural e um para a zona urbana (DATASUS 2009). Segundo os quilombolas, o cirurgião-dentista atende a comunidade de Cocalinho apenas um dia ao longo da semana, o que acaba acarretando a dificuldade de acesso, devido à demanda da população. Essa falta de acesso também pode ser uma realidade para outras comunidades quilombolas. Entre os quatro municípios que possuem populações quilombolas e que compõem a região de saúde do médio norte Araguaia (Tocantins 2020; IBGE 2019a, 2019b), dois não possuem a quantidade de cirurgiões-dentistas recomendada pela OMS (Santa Fé do Araguaia e Filadélfia); Aragominas e Muricilândia atendem ao recomendado, porém não há dados de saúde bucal nestas regiões para avaliar a efetividade do acesso (DATASUS 2009). É preciso ressaltar a necessidade de atualização dos dados do DATASUS e de realização de estudos em saúde bucal para populações quilombolas que permitam conhecer a atual situação de acesso aos serviços do SUS nessas comunidades do médio norte Araguaia.

O estudo de Tsang (2019) pôde afirmar que a mudança de hábitos nutricionais para dietas menos saudáveis, juntamente com a falta de informação sobre risco que a nova alimentação pode causar, é um fator crítico para o aumento de cárie, que também pode estar relacionada à desnutrição, principalmente em populações rurais, por isso a educação em nutrição e os hábitos de higiene oral devem estar juntos. No caso da relação de desnutrição e cárie dentária, outros fatores aparecem como causa, uma vez que a desnutrição pode ocasionar defeitos estruturais na formação do esmalte dentário durante esse processo de composição, tornando-o mais suscetível ao processo carioso, além de afetar as glândulas salivares, diminuindo e/ou alterando o fluxo salivar, causando desequilíbrio no processo des-re (Costa et al. 2010).

Apesar dos levantamentos de saúde bucal de base nacional apontarem para o declínio da cárie 
dentária na idade de 12 anos no Brasil (Brasil 2004, 2012), as ações de política pública nesse sentido não podem regredir, pois há muitas pessoas em situação vulnerável, tendo o SUS como única forma de acesso aos serviços de saúde bucal. Além disso, o SB Brasil 2010 (Brasil 2012) mostra índices altíssimos de CPOD em idades mais avançadas, além do aumento de cárie na primeira infância, porém esses resultados são subestimados pelos líderes, evidenciando apenas o questionável CPOD "baixo" para a idade de 12 anos. Há, ainda, muitos limites no avanço das políticas públicas em saúde bucal no Brasil, principalmente quando se refere às populações mais vulneráveis, como a comunidade quilombola do estudo.

Os resultados apresentados são indicativos de processos falhos para viabilizar as ações previstas na Agenda Social Quilombola, que previam assegurar o direito do acesso à saúde bucal e a obrigatoriedade da fluoretação das águas de abastecimento público, uma vez que é de suma importância para a prevenção de cárie dentária, principalmente em grupos mais vulneráveis (Dias et al. 2020; Bello \& Souza 2012; Figueiredo et al. 2016; Rodrigues et al. 2011). Portanto, podemos destacar a evidente privação de direitos básicos de saúde bucal, entre outros, para a comunidade de remanescentes quilombolas de Cocalinho.

\section{CONSIDERAÇÕES FINAIS}

A discussão relacionada aos dois estudos nos permite fazer um paralelo entre desenvolvimento e a SAN, como proposto por Kepple \& Segall Corrêa (2011), Gubert et al. (2016) e Leroy et al. (2015). Para estes autores, o desenvolvimento dependente das relações entre os determinantes sociais e econômicos na alteração da segurança alimentar e consequentes problemas de qualidade de vida das pessoas.

Os resultados dos indicadores de saúde nutricional na comunidade de Cocalinho evidenciaram que as políticas públicas para garantia da Segurança Alimentar e Nutricional (SAN), nesta população, não estão sendo aplicadas na sua totalidade, evidenciando a privação da comunidade de uma possível melhoria na qualidade de vida. Isto é um problema em nível nacional, relacionado à implantação das câmaras intersetoriais do Sistema Nacional de Segurança Alimentar e Nutricional (SISAN) que ocorre de forma heterogênea, pois há câmaras instaladas em todos os estados, mas somente $7,6 \%$ dos municípios reportaram possuir esta instância intersetorial (Brasil 2014b).

Uma particularidade vista em todo território é a de que as coordenações que tratam da SAN sempre estão a cargo de coordenações múltiplas, nas esferas estaduais e municipais, como as da saúde e assistência social. Comparando a participação da sociedade civil, temos uma expressiva diferença 
entre as duas políticas públicas: da saúde e da SAN, pois os movimentos sociais pela saúde são mais expressivos e historicamente marcados por maior empenho popular. É importante dizer que se refere ao fato de que os problemas da SAN se tornam secundários, e não se descarta a intersetorialidade dessas políticas, pois se faz imprescindível para o funcionamento do SISAN; só se chama atenção que, quando a SAN está subordinada a essas pastas, se torna uma necessidade secundária da gestão.

Atualmente, acompanha-se com preocupação a intenção da atual Presidência da República em extinguir o Conselho Nacional de Segurança Alimentar e Nutricional (CONSEA), por meio da Medida Provisória no 870, de 01 de janeiro de 2019, um fato que se repete ao longo da história de luta pela segurança alimentar e nutricional em nosso país. A fragilidade do processo de descentralização intersetorial pode ser explicada pelo fato de as ações terem que partir da esfera federal para depois terem como coadjuvante a participação da sociedade.

Aliado aos aspectos culturais e históricos, à geografia, à pobreza, à falta de educação e à falta de voz política das comunidades quilombolas, destaca-se um elevado grau de disparidade na saúde, isto é bem característico nessas populações, assim como nas demais populações que sofrem com problemas de saúde em consequência dos determinantes sociais. Isso não é diferente e, por muitas vezes, talvez seja mais marcante nas comunidades quilombolas. Ressalta-se que existem forças sociais e políticas que dificultam a melhora na saúde nessas comunidades, mas que devem ser questionadas diante de políticas públicas específicas e expressivas.

A realidade da comunidade, hoje, é representada pela falta de estímulos para produção agrícola local, atividade pautada na sua tradicionalidade, decorrente do conjunto de ocorrências negativas, históricas e sociais a que tem sido submetida. É possível dizer que, provavelmente, o desenvolvimento e o crescimento econômico estejam estagnados, e que o desenvolvimento humano atrelado a ele pode estar comprometido. Assim, é possível questionar quando essas comunidades irão, de fato, ser vistas como parte de um todo, em um país com variações bruscas de políticas mitigadoras de desigualdades.

O reconhecimento da comunidade de Cocalinho como tradicional não garantiu seu acesso ao desenvolvimento adequado e, neste sentido, ficou evidente que a efetivação da segurança alimentar e da saúde bucal no grupo exige profundas reflexões. Ressalta-se que os parâmetros apresentados neste trabalho necessitam de 
estudos pormenorizados e um acompanhamento longitudinal para elucidar as especificidades dos problemas detectados. Porém, cabe relatar que a falta de produtividade econômica, bem como a perda do espaço para plantio e consequente desaparecimento da produção agrícola tradicional, além da proximidade da comunidade com a zona urbana são determinantes na estagnação do desenvolvimento, para além do econômico, nesta população.

Os desajustes econômicos e sociais se associam à insegurança alimentar e nutricional na comunidade, como demonstrado na ingestão inadequada de alimentos, principalmente associada ao aumento do consumo de alimentos industrializados e consequente processo de transição nutricional e epidemiológica. Esse aumento, provavelmente, reflete, além da urbanização, as mudanças dos hábitos, do estilo de vida e a perda da soberania alimentar dos quilombolas, ocasionando, assim, problemas tanto na saúde geral como na saúde bucal.

Os dados epidemiológicos e avaliações transversais como essas são essenciais para subsidiar processos de planejamento, gestão e avaliação de políticas e ações voltadas à melhoria da segurança alimentar, segurança nutricional e saúde bucal. Esses resultados funcionam como instrumentos direcionadores de ações que trabalham no sentido de garantir as liberdades substantivas, uma vez que mostram variações populacionais, geográficas, temporais e culturais na distribuição dos índices, e revelam situações de desigualdade e demandas específicas.

$\mathrm{Na}$ saúde bucal, é possível considerar que, em Cocalinho, há privação de liberdade substantiva, pois existe dificuldade de acessar serviços básicos de saúde bucal preventivos e curativos, além da má nutrição, que nitidamente tem impactos negativos na saúde integral. Esse cenário implica diretamente a "capacidade" do indivíduo, que perde a percepção do que é necessário para o seu bem-estar. Portanto, as políticas públicas em saúde bucal devem ser elaboradas visando equidade para com os diferentes grupos populacionais e a pluralidade dos seus "espaços". Esses resultados podem servir de subsídio para implantação de serviços visando as especificidades dessas comunidades.

Em síntese, políticas públicas de incentivo à produção agroalimentar e de educação alimentar e nutricional que valorizem os alimentos regionais são relevantes para o processo de segurança alimentar e nutricional dessas comunidades. No entanto, é necessária a melhoria das condições de vida dessas populações, com maior acesso a serviços de educação e saúde em geral, incluindo os serviços odontológicos. 


\section{REFERÊNCIAS}

Almeida, J. B., K. O. Kian, R. C. Lima, e M. C. Souza. Total and abdominal adiposity and hypertension in indigenous women in Midwest Brazil. PLoS One 11(6):e0155528. DOI: http://doi.org/10.1371/journal. pone. 0155528

Alvim, R. O., C. A. Mourão-Junior, C. M. de Oliveira, J. E. Krieger, J. G. Mill, e A. C. Pereira. 2014. Body mass index, waist circumference, body adiposity index, and risk for type 2 diabetes in two populations in Brazil: general and ameríndian. PloS One 9(6):e100223. DOI: https://doi.org/10.1371/ journal.pone.0100223

Arantes, L. L., F. A. Martins, e R. Flit. 2014. Programa Brasil Quilombola: avanços e desafios, in Quilombos do Brasil: segurança alimentar e nutricional em territórios titulados (Cadernos de Estudos de Desenvolvimento Social em Debate, 20). Organizado por A. R. Pinto, J. C. Borges, M. P. Novo \& P. S. Pires, pp. 170-196. Brasília: Ministério do Desenvolvimento Social e Combate à Fome.

Bello, R. F., e M. C. A. Souza. 2012. Saúde bucal dos quilombolas valencianos: estudo transversal. Cadernos UniFOA 7:191.

Brasil. 1974. Lei n 6.050 de 24 de maio de 1974. Dispõe sobre a fluoretação da água em sistemas de abastecimento quando existir estação de tratamento. 1974. Diário Oficial da União.

Brasil. 1988. Constituição da República Federativa do Brasil. Brasília: Senado Federal/Centro Gráfico.

Brasil. 2003. Decreto $\mathrm{n}^{\circ}$ 4.887, de 20 de novembro de 2003. Regulamenta o procedimento para identificação, reconhecimento, delimitação, demarcação e titulação das terras ocupadas por remanescentes das comunidades dos quilombos de que trata o art. 68 do Ato das Disposições Constitucionais Transitórias. Diário Oficial da União. Disponível em: http://www.planalto.gov.br/ccivil_03/decreto/2003/d4887.htm. Acesso em: 26 maio 2020. 
Brasil. 2004. Diretrizes da Política Nacional de Saúde Bucal do Ministério da Saúde. Brasília: Ministério da Saúde.

Brasil. 2005. $3^{\text {a }}$ Conferência Nacional de Saúde Bucal: acesso e qualidade superando a exclusão social. Relatório final. Brasília: Ministério da Saúde. Disponível em: http://conselho.saude.gov.br/biblioteca/ Relatorios/saude_bucal.pdf. Acesso em: 26 maio 2020.

Brasil. 2006. Guia alimentar para a população brasileira. 1. ed. Brasília: Ministério da Saúde.

Brasil. 2007. Decreto ${ }^{\circ}$ 6.261, de 20 de novembro de 2007. Dispõe sobre a Gestão integrada para o desenvolvimento da Agenda Social Quilombola no âmbito do Programa Brasil Quilombola. Diário Oficial da União. Disponível em: http://www.planalto.gov.br/ccivil_03/_ato2007-2010/2007/decreto/ d6261.htm\#: :text=Decreto\%20n\%C2\%BA\%206261\&text=DECRETO\%20N\%C2\%BA\%206.261\%2C\%20 DE\%2020,que\%20lhe\%20confere\%20o\%20art. Acesso em: 04 abr. 2020.

Brasil. 2009. Portaria n ${ }^{\circ}$ 992, de 13 de maio de 2009 do Ministério da Saúde. Institui a Política Nacional de Saúde Integral da População Negra. Diário Oficial da União. Disponível em: http://bvsms.saude. gov.br/bvs/saudelegis/gm/2009/prt0992_13_05_2009.html\#: :text=Considerando\%20o\%20Decreto\%20 n\%C2\%B0,216\%20da\%20Constitui\%C3\%A7\%C3\%A3o\%2C\%20no\%20art. Acesso em: 24 jan. 2020.

Brasil. 2010. Ministério da Saúde. Projeto SB Brasil. Condições de saúde bucal da população brasileira. Brasília-DF: MDS. Disponível em: http://www.sbbrasil2010.org/. Acesso em: 26 maio 2020.

Brasil. 2012. Secretaria de políticas de promoção da igualdade Racial. Programa Brasil quilombola: diagnóstico das ações realizadas. Brasília-DF: MDH. Disponível em: https://www.mdh.gov.br/ biblioteca/igualdade-racial/diagnostico-de-acoes-realizadas-programa-brasil-quilombola. Acesso em: 26 maio 2020.

Brasil. 2014a. Guia alimentar para a população brasileira. 2. ed. Brasília: Ministério da Saúde. 
Brasil. 2014b. Mapeamento da insegurança alimentar e nutricional com foco na desnutrição a partir da análise do Cadastro Único e do SISVAN. Documento técnico. Estudo Técnico - CAISAN.

Brasil. 2016. Ministério da Saúde. VIGITEL: vigilância de fatores de risco e proteção para doenças crônicas por inquérito telefônico. Brasília: Secretaria de Vigilância em Saúde.

Burt, B. A., S. A. Eklund, K. J. Morgan, F. E. Larkin, K. E. Guire, L. O. Brown, e J. A. Weintraub. 1988. The effects of sugars intake and frequency of ingestion on dental caries increment in a three-year longitudinal study. Fournal of Dental Research 67:1422-1429. DOI: https://doi.org/10.1177/002203458 80670111201

Câmara Interministerial de Segurança Alimentar e Nutricional (CAISAN). Balanço das Ações do Plano Nacional de Segurança Alimentar e Nutricional PLANSAN 2012/2015. Brasília: 2014.

Carvalho, D. C. L. 2003. Avaliação in vitro do efeito do abacate, Hass, banana prata e maçã Fuji sobre a fermentação e a síntese de polissacarídeos extracelulares da placa dentária humana, Dissertação de Mestrado, Faculdade de Odontologia de Bauru, Universidade de São Paulo, Bauru.

Cavalcante, I. M. S. 2011. Acesso e acessibilidade aos serviços de saúde em três quilombos na Amazônia paraense: um olhar antropológico. Dissertação de Mestrado, Universidade Federal do Pará, Belém.

Cavalcante, I. M. S., e H. P. Silva. 2019. Políticas públicas e acesso aos serviços de saúde em quilombos na Amazônia paraense, in Quilombolas: aspectos políticos, jurídicos e políticas públicas inclusivas consequentes à edição do Decreto $n^{\circ} 4887-2003$ e do julgamento da ADI $n^{\circ} 3239$. Organizado por A. Fontes et al., pp. 473-498. Rio de Janeiro: TRF2.

Cavazzola, A. S. 2003. Avaliação dos efeitos dos chás de camomila, cidreira e erva doce sobre a fermentação e síntese de polissacarídeos na placa dentária humana: estudo in vitro. Dissertação de Mestrado, Faculdade de Odontologia de Bauru, Universidade de São Paulo, Bauru. 
Consultor Jurídico (Conjur). 2014. Município é o responsável por saneamento básico de quilombos, diz TRF-4. Revista Consultor furídico. Disponível em: https://www.conjur.com.br/2014-out-11/municipioresponsavel-saneamento-basico-quilombos-trf. Acesso em: 26 jun. 2010.

Cordeiro, M. M., E. T. Monego, e K. A. Martins. 2014. Overweight in Goiás' quilombola students and food insecurity in their families. Revista de Nutrição 27(4):405-412. DOI: https://doi.org/10.1590/141552732014000400002

Costa, D. P., A. C. M. Mota, G. B. Bruno, M. E. L. Almeida, e C. S. R. Fonteles. 2010. Desnutrição energético-protéica e cárie dentária na primeira infância. Revista de Nutrição 23(1):119-126. DOI: https://doi.org/10.1590/S1415-52732010000100013

DATASUS. 2009. Cadernos de Informações de Saúde do Tocantins. Brasília: Ministério da Saúde.

Dias, J. G., F. M. Pacifico, T. P. Borges, e P. C. C. Ribeiro. 2019. Polarização da cárie do Brasil, desigualdade e exclusão social: desdobramentos para a região Norte. Revista Querubim 4:84.

Dias,J. G., B. Pereira, P. Ribeiro, e L. Monteiro. 2020. Vulnerabilidade em saúde bucal: ausência de flúor na água de abastecimento público em uma comunidade remanescente quilombola. fournal Business Technologic 13(1):57-69.

Dietz, W. H. 1995. Does hunger cause obesity? Pediatrics 95(5):766-767.

Duarte, A. C. C. 2014. Mal oclusão, qualidade de vida e vulnerabilidade social em crianças brasileiras: estudo de base populacional, Tese de Doutorado, Universidade Federal de Minas Gerais, Faculdade de Odontologia, Belo Horizonte.

Durand, M., e I. Heidemann. 2019. Social determinants of a Quilombola Community and its interface with Health Promotion. Revista da Escola de Enfermagem da USP 53:e03451. DOI: https://doi.org/10.1590/ s1980-220x2018007703451 
Fávaro, T. R., R. V. Santos, G. M. Cunha, I. C. Leite, e C. E. Coimbra Jr. 2015. Obesidade e excesso de peso em adultos indígenas Xukuru do Ororubá, Pernambuco, Brasil: magnitude, fatores socioeconômicos e demográficos associados. Cadernos de Saúde Pública 31(8):1685-1697. DOI: https://doi.org/10.1590/0102311X00086014

Felisbino-Mendes, M. S., A. K. Jansen, C. S. Gomes, e G. Velásquez-Meléndez. 2014. Avaliação dos fatores de risco cardiovasculares em uma população rural brasileira. Cadernos de Saúde Pública 30(6):1183-1194. DOI: https://doi.org/10.1590/0102-311X00103213

Fidelis, L. 2011. Quilombos, agricultura tradicional e a agroecologia: o agroecossistema do quilombo João Surá sob a ótica da sustentabilidade. Cadernos CERU 22(1):57-72.

Figueiredo, M. C., B. P. Benvegnúll, P. P. L. Silveira, A. M. Silva, e K. V. C. Silva. 2016. Saúde bucal e indicadores socioeconômicos de comunidades quilombolas rural e urbana do Estado do Rio Grande do Sul, Brasil Revista da Faculdade de Odontologia de Lins 26(2):61-73. DOI: https://doi.org/10.15600/22381236/fol.v26n2p61-73

Freitas, D. A., A. D. Caballero, A. S. Marques, C. A. Hernández, A. Vergara, e N. S. L. Oliveira. 2011. Saúde e comunidades quilombolas: uma revisão da literatura. Revista CEFAC 13(5):937-943.

Fontoura, A. S., e C. M. Formetin. 2013. Guia prático de avaliação física: uma abordagem didática, abrangente e atualizada. 2. ed. São Paulo: Phorte Editora LTDA.

Food and Agriculture Organization of the United Nations (FAO). 1996. World Food Summit. Disponível em: http://www.fao.org/wfs/. Acesso em: 20 jan. 2019.

Food and Agriculture Organization of the United Nations (FAO). 2014. O estado da segurança alimentar e nutricional no Brasil: um retrato multidimensional. Relatório. Brasília: FAO. 
Fundação Cultural Palmares. (s/d). Informações Quilombolas. Disponível em: palmares.gov.br/?page_ id=52126\#: :text=De\%20todo\%20modo\%2C\%20temos\%20que,tem\%20com\%20a\%20população\%20negra. Acesso em: 10 jun. 2020.

Fundação Cultural Palmares. 2020. Tabela de CRQ completa. Disponível em: http://www.palmares.gov. br/sites/mapa/crqs-estados/crqs-to-21022020.pdf. Acesso em: 26 maio 2020.

Fundação João Pinheiro (FJP). 2017. Desenvolvimento humano para além das médias: 2017. Brasília: PNUD/IPEA/FJP.

Google Earth. (2020). Disponível em: https://www.google.com.br/intl/pt-BR/earth/. Acesso em: 26 maio 2020.

Gubert, M. B., A. M. Segall-Corrêa, A. M. Spaniol, J. Pedroso, S. E. D. A. C. Coelho, e R. PérezEscamilla. 2016. Household food insecurity in black-slaves descendant communities in Brazil: has the legacy of slavery truly ended? Public Health Nutrition 20(8):1513-1522. DOI: http://doi.org/10.1017/ S1368980016003414

Hoffmann, R. 1995. Pobreza, insegurança alimentar e desnutrição no Brasil. Estudos Avançados 29(4):159-172. DOI: https://doi.org/10.1590/S0103-40141995000200007

Instituto Brasileiro de Geografia e Estatística (IBGE). 2010. Bases e referências cartográficas. Disponível em: https://mapas.ibge.gov.br/bases-e-referenciais/bases-cartograficas/malhas-digitais. Acesso em: 26 de maio 2020.

Instituto Brasileiro de Geografia e Estatística (IBGE). 2012. Disponível em: http://www.ibge.gov.br. Acesso em: 10 mar. 2020.

Instituto Brasileiro de Geografia e Estatística (IBGE). 2018. Cidades: Santa Fé do Araguaia. Disponível em: https://cidades.ibge.gov.br/brasil/to/santa-fe-do-araguaia/panorama. Acesso em: 21 set. 2018. 
Instituto Brasileiro de Geografia e Estatística (IBGE). 2019a. Mapa das Localidades Quilombolas. Disponível em: https://quilombolasibgedgc.hub.arcgis.com/app/114dc1672a85401a9fdbebbb857e5e58. Acesso em: 08 jul. 2010.

Instituto Brasileiro de Geografia e Estatística (IBGE). 2019b. Cadastro de Comunidades Quilombolas. Disponível em: https:/quilombolasibgedgc.hub.arcgis.com/app/8d714bee42bb48b481c11841f10352f3. Acesso em: 26 maio 2020.

Instituto Nacional de Colonização e Reforma Agrária (INCRA). (s/d). Disponível em: http://certificacao. incra.gov.br/csv_shp/export_shp.py. Acesso em: 26 maio 2020.

Kamakura, W. A, e J. A. Mazzon. 2013. Estratificação socioeconômica e consumo no Brasil. São Paulo: Blucher.

Kepple, A. W., e A. M. Segall-Corrêa. 2011. Conceituando e medindo segurança alimentar e nutricional. Ciência \& Saúde Coletiva 16(1):187-199. DOI: http://dx.doi.org/10.1590/S1413-81232011000100022.

Kursmark, M., e M. Weitzman. 2009. Recent findings concerning childhood food insecurity. Current Opinion in Clinical Nutrition \& Metabolic Care 12(3):310-316.

Lavinas, L. 2002. Pobreza e exclusão: traduções regionais de duas categorias da prática. Econômica 4:25-59.

Leroy, J. L., M. Ruel, E. A. Frongillo, J. Harris, e T. J. Ballard. 2015. Measuring the Food Access Dimension of Food Security: A Critical Review and Mapping of Indicators. Food and Nutrition Bulletin 36(2):167195. DOI: https://doi.org/10.1177/0379572115587274

Lima, J. E. O. 2007. Cárie dentária: um novo conceito. Revista Dental Press Orthodontic and Orthopedic Facial 12(6):119-130. DOI: https://doi.org/10.1590/S1415-54192007000600012 
Louzada, M. L. C., A. P. B. Martins, D. S. Canella, L. G. Baraldi, R. B. Levy, R. M. Claro, J.-C. Moubarac, G. Cannon, e C. A. Monteiro. 2015. Ultra-processed foods and the nutritional dietary profile in Brazil. Revista de Saúde Pública 49:38. DOI: https://dx.doi.org/10.1590/S0034-8910.2015049006132

Luisi, C., F. Figueiredo, L. V. Sousa, F. R. Quaresma, E. Maciel, e F. Adami. 2019. Prevalence of and factors associated with metabolic syndrome in afro-descendant communities in a situation of vulnerability in Northern Brazil: a cross-sectional study. Metabolic Syndrome and Related Disorders 17(4):204-209.

Mahan, K., S. Escott-Stump, e J. L. Raymond. 2018. Krause alimentos, nutrição e dietoterapia. Rio de Janeiro: Elsevier.

Matheus, D. J. 2010. Vulnerability related to oral health in early childhood: a concept analysis. Fournal of Advanced Nursing 66:2116-2125.

Mendes, P. M. 2006. Segurança alimentar em comunidades quilombolas: estudo comparativo de Santo Antônio (Concórdia do Pará) e Cacau (Colares), Pará, Dissertação de Mestrado, Universidade Federal do Pará, Belém.

Mingroni-Netto, R., C. K. L. Angeli, M. Auricchio, e J. Vicente. 2009. Doenças modernas nos antigos quilombos: a obesidade e a hipertensão no Vale do Ribeira, in Saúde nos quilombos. Organizado por A. Volochko \& L. E. Batista, pp. 179-191. São Paulo: Instituto da Saúde.

Monego, E. T., M. R. G. Peixoto, M. Morais Cordeiro, e R. M. Costa. 2010. (In)segurança alimentar de comunidades quilombolas do Tocantins. Segurança Alimentar e Nutricional 17(1):37-47. DOI: https:// doi.org/10.20396/san.v17i1.8634798

Moore, W. J, e M. E. Corbett. 1971. The distribution of dental caries in ancient British populations. Anglo-saxon period. Caries Research 5(2):151-168. DOI: https://doi.org/10.1159/000259743 
Morais, M. R. 2012. Políticas públicas e a fé afro-brasileira: uma reflexão sobre ações de um estado laico. Ciencias Sociales y Religión/Ciências Sociais e Religião 14(16):39-59.

Moratoya, E. E., G. C. Carvalhares, A. E. Wander, e L. M. M. C. Almeida. 2013. Mudanças no padrão de consumo alimentar no Brasil. Revista de Política Agrícola 22(1):72-84.

Narvai, P. C., P. Frazão, R. A. Giuseppe, e J. L. F. Antunes. 2006. Cárie dentária no Brasil: declínio, polarização, iniqüidade e exclusão social. Revista Panamericana de Salud Pública 19(6):385-393.

Oliveira, G. A. 2018. Pegos a laço: identidade, deslocamento e luta pela terra no quilombo de Cocalim, Tese de Doutorado, Universidade Estadual Paulista, Faculdade de Filosofia e Ciências, São Paulo.

Okop, K. J., N. Levitt, e T. Puoane. 2015. Factors associated with excessive body fat in men and women: cross-sectional data from black South Africans living in a rural community and an urban township. PloS One 10(10):e0140153. DOI: https://doi.org/10.1371/journal.pone.0140153

Paiva, S. G. 2017. Fatores de risco para doenças cardiovasculares em populações de quilombos contemporâneos do Brasil central: parâmetros demográficos, socioeconômicos, ancestralidade genética e saúde, Tese de Doutorado, Universidade de Brasília, Brasília.

Paiva, S. G., C. C. Gontijo, R. C. Gontijo, L. L. Madrigal, e M. N. Klautau-Guimarães. 2020. Migration in Brazilian afro-descendants communities: a new approach to illustrate the meaning of contemporary Quilombo. Revista da ABPN 12(32): 188-208.

Pedraza, D. F., e Nobre, T. N. 2014. Questionários de Frequência de Consumo Alimentar desenvolvidos e validados para população do Brasil: revisão da literatura. Ciência \& Saúde Coletiva 20(9):2697-2720. DOI: https://doi.org/10.1590/1413-81232015209.12602014

Pena, G. G., A. Martinez-Perez, M. S. Dutra, A. Gazzinelli, R. Correa-Oliveira, J. M. Soria, e G. Velasquez- 
Melendez. 2016. Genetic determinants of cardiometabolic risk factors in rural families in Brazil. American fournal Human Biology 28(5):619-626. DOI: https://doi.org/10.1002/ajhb.22842

Piperata, B. A., S. A. Ivanova, P. Da-Gloria, G. Veiga, A. Polsky, J. E. Spence, e R. S. Murrieta. 2011. Nutrition in transition: dietary patterns of rural Amazonian women during a period of economic change. American fournal of Human Biology 23(4):458-469. DOI: http://doi.org/10.1002/ajhb.21147

Rodrigues, S. A., M. G. Lucas, S. T. S. Cerqueira, A. S. Braga, e L. G. Vaz. 2011. Educação em saúde em comunidades quilombolas. Revista Gaúcha de Odontologia 59(3):445-451.

Salles-Costa, R., R. A. Pereira, M. T. L. Vasconcellos, G. V. Veiga, V. M. Ramos, B. C. Jardim, F. S. Gomes, e R. Sichieri, 2008. Associação entre fatores socioeconômicos e insegurança alimentar: estudo de base populacional na região metropolitana do Rio de Janeiro, Brasil. Revista de Nutrição 21:99-109.

Santos R. D., A. C. M. Gagliardi, H. T. Xavier, C. D. Magnoni, R. Cassani, e A. M. Lottenberg. 2013. Sociedade Brasileira de Cardiologia. I Diretriz sobre o consumo de gorduras e saúde cardiovascular. Arquivos Brasileiros de Cardiologia 100(Supl.3):1-40.

Santos, L. P., M. G. Costa, J. V. Santos, I. L. Lindemann, e D. P. Gigante. 2014. Comparação entre duas escalas de segurança alimentar. Ciência \& Saúde Coletiva 19(1):279-286. DOI: https://doi.org/10.1590/141381232014191.2058

Sardinha, L. M. V, R. Campos, O. S. Pires, e P. Jannuzzi. 2014. Análise das condições de vida, segurança alimentar e nutricional e acesso a programas sociais em comunidades quilombolas tituladas, in Quilombos do Brasil: segurança alimentar e nutricional em territórios titulados (Cadernos de Estudos de Desenvolvimento Social em Debate, 20). Organizado por A. R. Pinto, J. C. Borges, M. P. Novo \& P. S. Pires, pp. 31-52. Brasília: Ministério do Desenvolvimento Social e Combate à Fome. 
Schlüssel, M. M., A. A. M. Silva, R. Pérez-Escamilla, e G. Kac. 2013. Household food insecurity and excess weight/obesity among Brazilian women and children: a life-course approach. Cadernos de Saúde Pública 29(2):219-226. DOI: https://doi.org/10.1590/S0102-311X2013000200003

Schmidt, G. F. 2001. Perda precoce do primeiro molar permanente, Monografia de Especialização em Odontopediatria, Universidade Federal de Santa Catarina, Florianópolis.

Schramm, J. M. A., A. F. Oliveira, I. C. Leite, J. G. Valente, A. M. J. Gadelha, M. C. Portela, e M. R. Campos. 2004. Transição epidemiológica e o estudo de carga de doença no Brasil. Ciência \& Saúde Coletiva 9(4):897-908. DOI: https://doi.org/10.1590/S1413-81232004000400011

Silva, H. P., B. A. Piperata, e D. L. Dufour. 2016. Human biology of the Amazon. Annals of Human Biology 43(4):289-292. DOI: https://doi.org/10.1080/03014460.2016.1197546

Silva, E. K. P., D. S. Medeiros, P. C. Martins, L. A. Sousa, G. P. Lima, M. A. S. Rêgo, T. O. Silva, A. S. Freire, e F. M. Silva. 2017. Insegurança alimentar em comunidades rurais no Nordeste brasileiro: faz diferença ser quilombola? Cadernos de Saúde Pública 33(4):e00005716. DOI: https://doi.org/10.1590/0102$311 \times 00005716$

Silva, M. J. O., C. S. Silva, C. H. F. Silva, e S. V. Carneiro. 2018. Condição de saúde bucal de população de 11 a 15 anos de idade em comunidade quilombola Sítio Veiga. Revista Cereus 10(3):79-91. DOI: https://doi.org/10.18605/2175-7275/cereus.v10n3p79-91

Silva, S. D. S., e R. P. Santos. 2018. Populações tradicionais: uma reflexão sobre a questão nutricional. Amazônica - Revista de Antropologia 10(2):552-566. DOI: http://dx.doi.org/10.18542/amazonica.v10i2.6517

Sociedade Brasileira de Cardiologia (SBC). 2013. I Diretriz Brasileira de Prevenção Cardiovascular 101(6):Suplemento 2. Disponível em: http://publicacoes.cardiol.br/consenso/2013/Diretriz_Prevencao_ Cardiovascular.pdf. Acesso em: 28 set. 2020. 
Soares, L. P., A. L. Dal Fabbro, A. S. Silva, D. S. Sartorelli, L. F. Franco, P. C. Kuhn, R. S. Moises, J. P. B. Vieira-Filho, e L. J. Franco, 2015. Prevalence of metabolic syndrome in the Brazilian Xavante indigenous population. Diabetology \& Metabolic Syndrome 7(1):105. DOI: http://dx.doi.org/10.1186/ s13098-015-0100-x

Sousa, B. C., D. S. Medeiros, M. H. S. Curvelo, E. K. P. Silva, C. S. S. Teixeira, V. M. Bezerra, R. Souza, e A. J. M. Leite. 2019. Hábitos alimentares de adolescentes quilombolas e não quilombolas da zona rural do semiárido baiano, Brasil. Ciência \& Saúde Coletiva 24(2):419-430. DOI: https://doi.org/10.1590/141381232018242.34572016

Tocantins-SEPLAN. 2012. Secretaria da Fazenda e Planejamento. Base de dados geográficos do Tocantins. Disponível em: http://www.sefaz.to.gov.br/zoneamento/bases-vetoriais/bases-vetoriais/base-de-dadosgeograficos-do-tocantins---atualizacao-2012/. Acesso em: 28 set. 2020.

Tocantins. 2020. Secretaria de Saúde do estado do Tocantins: regionalização da saúde Tocantins história e mapas. Disponível em: https://saude.to.gov.br/planejamento-/regionalizacao-da-saude--desenvolvimento-de-politicas-de-saude/regionalizacao-da-saude-tocantins---historia-e-mapas/. Acesso em: 28 set. 2020.

Tsang, C., K. Sokal-Gutierrez, P. Patel, B. Lewis, D. Huang, K. Ronsin, A. Baral, A. Bhatta, N. Khadka, H. Barkan, e S. Gurung. 2019. Early Childhood Oral Health and Nutrition in Urban and Rural Nepal. International fournal of Environmental Research and Public Health 16(14):2456. DOI: https://doi. org/10.3390/ijerph16142456

Velho, O. G. 2009. Frente de expansão e estrutura agrária: estudo do processo de penetração numa área da Transamazônia. Rio de Janeiro: Centro Edelstein de Pesquisas Sociais.

World Health Organization (WHO). 1993. Calibration of examiners for oral health epidemiological surveys. Geneva: ORH/EPID. 
Apêndice 1 - Distribuição do consumo da variedade de alimentos não industrializados (A) e industrializados (B), com amostra para a comunidade Remanescente Quilombola de Cocalinho em Santa Fé do Araguaína, Tocantins.
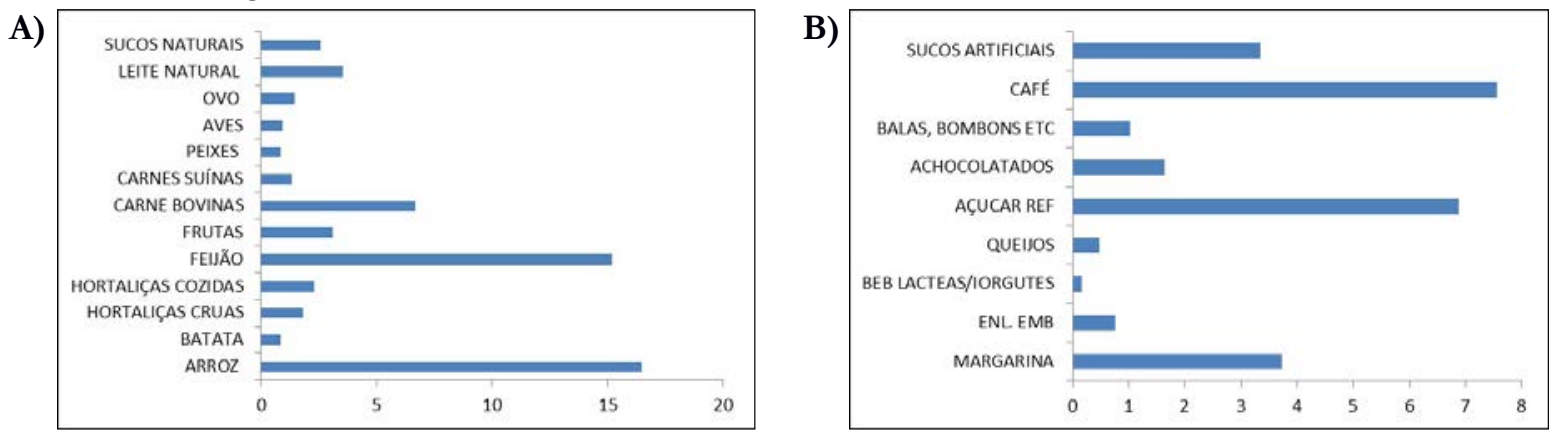

Apêndice 2 - Grupos alimentares baseados nos alimentos do QFA utilizado na pesquisa.

\begin{tabular}{|c|}
\hline PROTEÍNAS \\
\hline Carnes bovinas; carnes suínas; peixes; aves e feijão. \\
\hline CARBOIDRATOS \\
\hline Arroz branco; macarrão instantâneo; fubá; cuscuz de milho ou arroz; batata; \\
\hline pão de forma; pão francês; biscoito recheado; biscoito comum; bolo. \\
\hline GORDURAS \\
\hline Margarina ou manteiga e óleo de soja. \\
\hline AÇÚCARES \\
\hline Açúcar refinado; achocolatados; doces caseiros; balas; bombons; \\
\hline sucos artificiais; sucos de caixinha; refrigerantes; café com açúcar. \\
\hline HORTALIÇAS E FRUTAS cruas; hortaliças cozidas; frutas. \\
\hline
\end{tabular}


Apêndice 3 - Questionário sobre segurança alimentar nutricional (EBIA).

Nos últimos 12 meses:

1. Alguma vez terminou a comida da casa e o(a) Sr.(a) não tinha dinheiro para comprar mais? $\operatorname{SIM}($ ) N N N $\quad$ N ( )

2. $\mathrm{O}$ (a) Sr.(a) pode oferecer uma alimentação variada, com feijão, arroz, carnes, saladas e frutas para sua família?

$\operatorname{SIM}($ ) NÃO ( )

3. $\mathrm{O}$ (a) Sr.(a) ou alguma outra pessoa na sua casa tiveram que diminuir a quantidade de comida ou não fazer alguma refeição por falta de dinheiro para comprar mais?

$\operatorname{SIM}($ ) N N N $\quad$ N ( )

Se SIM: Em quantos meses isso aconteceu?

4. $\mathrm{O}$ (a) Sr.(a) comeu menos do que gostaria porque não tinha dinheiro para comprar mais?

$\operatorname{SIM}($ ) NÃO ( )

5. $\mathrm{O}(\mathrm{a}) \mathrm{Sr}$.(a) sentiu fome, mas não comeu, porque não tinha dinheiro para comprar mais comida?

$\operatorname{SIM}($ ) NÃO ( ) 